\title{
Partnering with frail or seriously ill patients in research: a systematic review
}

\author{
Claire Ludwig ${ }^{1}$, lan D. Graham², Wendy Gifford', Josee Lavoie ${ }^{3}$ and Dawn Stacey ${ }^{1,4^{*}}$ (D)
}

\begin{abstract}
Background: The expectation to include patients as partners in research has steadily gained momentum. The vulnerability of frail and/or seriously ill patients provides additional complexity and may deter researchers from welcoming individuals from this patient population onto their teams. The aim was to synthesize the evidence on the engagement of frail and/or seriously ill patients as research partners across the research cycle.

Methods: A systematic review was conducted using PRISMA guidelines. A search strategy included MEDLINE ${ }^{\circledast}$, EMBASE ${ }^{\oplus}$, Cumulative Index to Nursing and Allied Health Literature (CINAHL), and PsyclNFO from database inception to April, 2019. Eligible studies were peer-reviewed qualitative, quantitative, and mixed methods research reporting on the engagement of frail and/or seriously ill patients as partners on research teams. The Mixed Methods Appraisal Tool was used to appraise study quality. Narrative analysis was conducted.
\end{abstract}

Results: Of 8763 citations, 30 were included. Most studies included individuals with cancer on the research team (60\%). Barriers included: lack of time and resources (50\%), discontinuity in contribution (37\%), and concerns for wellbeing (33\%). Facilitators included: trust and mutual respect (60\%), structural accessibility (57\%), flexibility in timing and methods of engagement (43\%), and attention to care and comfort, (33\%). Perceived impacts for patients included: renewed personal sense of agency (37\%) and emotional/peer support (37\%). Impacts for researchers included sensitization to the lived experience of disease (57\%) and an increased appreciation of the benefits of patient engagement (23\%). Research design, execution, and outcomes, developed with patients, were deemed more suitable, relevant and reflective of patients' priorities.

Conclusions: There is emerging evidence to suggest that research partnerships with frail and/or seriously ill patients can be achieved successfully. Patients mostly report benefit from partnering with research teams. Frailty and/or serious illness do present legitimate concerns for their well-being but appear to be successfully mitigated when researchers ensure that the purpose of engagement is well-defined, the timing and methods of engagement are flexible, and the practical and emotional needs of patient partners are addressed throughout the process.

Systematic review registration: The systematic review protocol was registered with the International Prospective Register of Systematic Reviews PROSPERO (CRD42019127994).

Keywords: Patient engagement, Public patient involvement, Systematic review, Integrated knowledge translation, Co-production

\footnotetext{
* Correspondence: dstacey@uottawa.ca

'University of Ottawa, Faculty of Health Sciences, School of Nursing, Roger

Guindon Hall, 451 Smyth Road, Ottawa, Ontario K1H 8M5, Canada

${ }^{4}$ Ottawa Hospital Research Institute, Clinical Epidemiology Program, 501

Smyth Road, Ottawa, Ontario K1H 8L6, Canada

Full list of author information is available at the end of the article
}

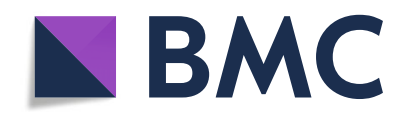

(c) The Author(s). 2020 Open Access This article is licensed under a Creative Commons Attribution 4.0 International License, which permits use, sharing, adaptation, distribution and reproduction in any medium or format, as long as you give appropriate credit to the original author(s) and the source, provide a link to the Creative Commons licence, and indicate if changes were made. The images or other third party material in this article are included in the article's Creative Commons licence, unless indicated otherwise in a credit line to the material. If material is not included in the article's Creative Commons licence and your intended use is not permitted by statutory regulation or exceeds the permitted use, you will need to obtain permission directly from the copyright holder. To view a copy of this licence, visit http://creativecommons.org/licenses/by/4.0/. The Creative Commons Public Domain Dedication waiver (http://creativecommons.org/publicdomain/zero/1.0/) applies to the data made available in this article, unless otherwise stated in a credit line to the data. 


\section{Plain English summary}

Patients are experts by experience and are becoming more active as partners on research teams. Patients who are frail and/or seriously ill do not appear to be engaged as research partners to the same extent as those living with more stable illness. The aim of this systematic review was to explore how frail and/or seriously ill patients have been engaged as partners in research.

In 30 studies, frail and/or seriously ill patients were engaged as research partners. They identified: research questions and outcomes important to patients; developed tools and processes more related to patients' needs and experiences; helped collect and/or interpret findings; presented research results; and provided study oversight. Barriers to patients' partnering were mostly related to concerns about their fragile health, their ability to process information and their likely limited ability to partner for the duration of the study due to declining health or death. When frail and/or seriously ill patients were engaged as partners in research, patients had a renewed sense of purpose and felt emotional support, research was more related to patients' needs, and researchers gained greater insight into the lived experience of illness and suffering. Overall, it appears that frail and/ or seriously ill patients can and should be included as research partners. Researchers can work to avoid unduly harming patient partners by being flexible and ensuring patients' physical and emotional needs are addressed during the research process.

\section{Background}

Over the past two decades, the commitment to engaging patients as partners in research has steadily gained momentum. International interest in patient engagement has been fostered by the belief that it can enhance the relevance, validity, and quality of research [1]. It is further postulated that research developed in this way will be more applicable to the needs of patients and hence more readily applied $[2,3]$; thereby, legitimizing research that is often publicly funded $[4,5]$. Patient engagement has become a moral and ethical imperative and, in some jurisdictions, particularly with marginalized communities, patient engagement also serves as a pre-requisite for research ethics approval [6-8]. The engagement of patients as partners in the design, execution and evaluation of health research is now an expectation of several principal funding programs $[5,9]$.

In Canada, as in many other countries, most major national and provincial research funding bodies promote engagement of patients throughout the entire process, from determining the research question to dissemination of the research results $[10,11]$. A systematic review of 142 studies [2] established that, in most instances, it was possible for patients to contribute their expertise across the continuum of research; however, their engagement tended to be focused in the early stages of the study. The level of patient engagement in the process has varied in intensity and complexity depending on the nature of the research and information needs [11]. A more recent scoping review examining methods and outcomes of patient engagement confirmed that, in the absence of a validated framework, most efforts to engage patients continued to be limited to the early stages of engagement and did not appear to be maintained throughout the lifecycle of most research projects [12].

\section{Engaging patients as research partners}

Patients are broadly defined as individuals with personal experience of a health condition [11]. There are numerous terms used for the concept of patient engagement in research including, but not limited to: 'integrated knowledge translation', 'patient and public involvement', 'participation', 'patient engagement', 'public and patient engagement' and 'co-production' [13, 14]. Patient engagement can be considered along a continuum from consultation at one end of the spectrum to partnership at the other end of the spectrum of engagement [15]. Research partnership is identified as patient membership on the research team, contributing to shared decision-making across the research process, engaged in the planning, execution and dissemination of research findings [15].

When partnering with patients, there is a shift from the researcher as sole expert to one where researchers and patients are both experts, working together to solve problems and co-generate knowledge [16]. Patients' experiential knowledge (of illness) is not accessible to most researchers, but if leveraged appropriately, has the potential to complement researchers' analytical skills and scientific perspective ([17] , p. 676). The concept of partnering with patients as equal team members has been demonstrated in clinical guideline development [18], by systematic review teams [19], and in the area of health and services improvement [20]. However, there are ongoing concerns about the need to balance rights to participation with efficiency and outcomes, [21, 22], particularly in disciplines that may lack the necessary infrastructure to support patient-facing activities (e.g., preclinical research) [23, 24].

\section{Partnering with frail and/or seriously ill patients}

Inclusivity is an important principle in meaningful research partnerships with patients and places emphasis on equity of engagement in research $[25,26]$. Whilst a number of reviews have concentrated on descriptions of the process and methods for various levels of patient engagement, little attention has been directed towards providing detailed accounts of patient characteristics $[2,12$, 
15, 27]. This oversight makes it difficult to gauge the inclusion of individuals from diverse patient populations.

The vulnerability of certain groups, such as frail and/ or seriously ill patients (e.g., elderly patients with limited functional capacity, patients with high symptom burden, palliative patients), provides additional complexity to the engagement processes for prolonged and more intensive patient partnerships [27-29]. Frailty is classified as: a) geriatric condition involving functional decline, with increasing vulnerability to adverse events including mortality, morbidity, disability, hospitalization, and nursing home admission [30], or b) presence of multiple chronic conditions such as arthritis, heart failure, renal failure, and pulmonary disease leading to changes in functional ability [31], or c) presence of cognitive decline and dementia [30,32]. Older adults living with frailty are a diverse group of patients that exhibit physical and/or cognitive impairments. Serious illness is defined as a condition that carries a high risk of mortality, negatively impacts quality of life and daily function, and/or is burdensome in symptoms or treatments [33]. Examples of serious illnesses are cancer (e.g., metastatic or hematologic), advanced liver disease, and advanced pulmonary diseases [33].

Patients who are frail and/or seriously ill have unique needs associated with symptoms related to their condition and/or treatment side effects which may offer researchers' access to a lived experience of illness that is qualitatively different than those with more stable or chronic conditions [29]. Practical issues related to engaging frail and/or seriously ill patients as research partners appears to deter research teams from inviting, or even considering them for membership on the research team [28]. A recent scoping review exploring engagement of geriatric oncology patients found little evidence of patients' inclusion as research partners [29]. Little is known about the engagement of frail and/or seriously ill patients as partners on research teams.

\section{Aim}

The aim was to synthesize the evidence on the engagement of frail and/or seriously ill patients as research partners across the research cycle. The specific objectives were to: a) describe the contribution of frail and/or seriously ill patient partners to the stages of the research cycle (and associated research activities), b) identify the barriers and facilitators to partnering encountered by frail and/or seriously ill patients, and researchers, and c) describe the perceived positive and negative impacts of including frail and/or seriously ill patient partners in research from the perspective of patients, researchers, and the research itself.

\section{Methods/design Study design}

A systematic review of qualitative, quantitative, and mixed methods studies was conducted with narrative synthesis. The Preferred Reporting Items for Systematic Reviews and Meta-Analyses (PRISMA) [34] guided the reporting. The study protocol was developed prior to the literature search and registered via PROSPERO (CRD42019127994).

\section{Guiding conceptual framework}

The systematic review was guided by a conceptual framework comprised of two components (see Table 1). The first component utilizes a modified version of the Patient Service User Engagement in Research Framework originating from a prior systematic review by Shippee et al. [15], and addresses patient engagement at different stages of the research cycle and associated activities. The second component addresses the level of engagement in the decision-making process as defined by the International Association of Public Participation (IAP2) Spectrum of Public Participation (see Supplementary file 1 for additional detail) [35]. The IAP2 spectrum denotes five levels of engagement (inform, consult, involve, collaborate, and empower) and has been used in Canada, Australia, New Zealand, Indonesia, Italy, Southern Africa and the USA to outline levels of engagement and promote best practices in patient and public engagement [36].

\section{Data sources and search strategy}

An electronic search strategy was developed with the assistance of an experienced health sciences librarian (KF) and adapted for the following databases: MEDLINE (via Ovid), Cumulative Index to Nursing and Allied Health Literature (CINAHL via EBSCO), Excerpta Medica database (EMBASE ${ }^{\bullet}$ via Ovid), and PsycINFO $^{\circ}$ (via Ovid). The search strategy included a combination of key words and medical subject headings $(\mathrm{MeSH})$ terms such as "patient engagement", "patient involvement", "patientoriented research". (see Supplementary file 2 for the complete Medline search strategy). Reference lists of the included studies were manually reviewed to maximize the breadth of the review. There were no date limitations. The search strategy was executed from April 4, 2019 to April 6, 2019.

\section{Eligibility criteria}

The population, intervention, control, outcomes, study design (PICOS) criteria were used to assess study eligibility [34] (see Table 2). All original studies of any design were eligible if they included frail and/or seriously ill patients as research partners at the level of involvement, collaboration, or empowerment throughout the research 
Table 1 Guiding conceptual framework for engaging frail and/or seriously ill patients in research

\begin{tabular}{l}
\hline Stages of Research Cycle ${ }^{\mathbf{a}}$ \\
\hline Foundational phase \\
- Research priority setting - specific to disease, condition \\
syndrome \\
- Setting evidence-based patient engagement strategies \\
cific to disease, condition, or syndrome \\
Preparatory phase \\
- Agenda setting at the individual study level \\
- Proposal development \\
- Ethics application - including well-defined consent \\
procedures \\
- Acquiring funding/grant application
\end{tabular}

\section{Execution phase}

- Study design \& procedures

- Recruitment strategies \& tools

- Data collection

- Data analysis (reviewing \& interpreting data)

\section{Translation phase}

- Dissemination

- Implementation

- Evaluation

\section{IAP2 Spectrum of Public Participation ${ }^{\text {b }}$}

\section{Inform}

- Providing balanced and objective information to assist in understanding the problem, alternatives, opportunities and/or solutions

\section{Consult}

- Seeking/obtaining feedback on analysis, alternatives and/or decisions

\section{Involve}

- Working directly with (patients) throughout the process to ensure concerns and aspirations are consistently understood and considered

\section{Collaborate}

- Partnering in each aspect of the decision (e.g., contributing to shared decisionmaking across the research process)

Empower

- Patients and members of the public provide final decision.

${ }^{a}$ Modified from Shippee et al. (2015) [15]

${ }^{\mathrm{b}}$ Based on the IAP2 Spectrum of Public Participation (2014) [35]

Table 2 Study eligibility criteria: Modified (PICOS) Framework

\begin{tabular}{|c|c|c|}
\hline $\mathrm{PICOS}$ [34] & Inclusion Criteria & Exclusion Criteria \\
\hline $\begin{array}{l}\text { Participants } \\
\text { (P) }\end{array}$ & $\begin{array}{l}\text { - Frail and/or seriously ill adult patients as per definitions for } \\
\text { frailty and serious illness (e.g., elderly patients exhibiting } \\
\text { physical and/or cognitive impairments, patients with high } \\
\text { symptom burden due to acute illness or treatment effects, } \\
\text { acute episodic illness, palliative patients; patients susceptible } \\
\text { to adverse events including mortality, morbidity, disability, } \\
\text { hospitalization, and nursing home admission). }\end{array}$ & $\begin{array}{l}\text { - Studies where patients were excluded due to frailty of condition } \\
\text { (physical and or cognitive) or deemed too ill to participate } \\
\text { during acute episodes of serious illness or treatment. } \\
\text { - Patients not identified as frail or seriously ill, i.e., survivors, chronic } \\
\text { disease (focus on single disease without description of acuity/ } \\
\text { severity of condition). } \\
\text { - Participants from broader community or public engagement } \\
\text { (with no descriptors of frailty and serious illness) } \\
\text { - Patients for whom there were no descriptors of physical } \\
\text { characteristics or cognitive status. } \\
\text { - Pediatric and youth patients (<18yrs). }\end{array}$ \\
\hline $\begin{array}{l}\text { Phenomenon } \\
\text { of Interest (I) }\end{array}$ & $\begin{array}{l}\text { - Engagement of frail and/or seriously ill patients as partners in } \\
\text { research, i.e., at the level of involvement, collaboration, } \\
\text { empowerment. }\end{array}$ & $\begin{array}{l}\text { - Engagement of patients as objects of study, i.e., doing research } \\
\text { on or to. } \\
\text { - Engagement that took the form of informing patients of } \\
\text { research activities, or at the level of consultation only. }\end{array}$ \\
\hline
\end{tabular}

Comparator No comparator

(C)

Outcome (0) - Methods and timing of engagement (i.e., stage(s) of research process).

- Level of engagement

- Engagement strategies, factors associated with barriers and facilitators to engagement.

- Positive and/or negative impacts of engagement on patient(s), researcher(s), research and/or ethical concerns.

Study Type - Peer-reviewed qualitative, quantitative, or mixed methods (S) studies.

- Primary research outcomes where patients were research participants only.

- Letters

- Commentaries/editorials.

- Studies reported in non-peer reviewed journals.

- Conference abstracts/ presentations.

- Dissertations.

- Review articles. 
cycle (see Table 1). There were no language restrictions. In order to limit duplication, all systematic reviews were excluded after manually searching the reference lists of relevant reviews. Commentaries and editorials were excluded as well as studies that did not provide any details on patient perspectives or patient condition and when no full text was available.

\section{Study selection}

Search results were uploaded to Covidence Systematic Review Software [37]. Following the removal of duplicates, citations were screened independently by two reviewers (CL, JL) based on title and abstract (level 1 screening) and full-text articles (level 2 screening). The studies were assessed against the inclusion and exclusion criteria. Full-texts that did not meet the eligibility criteria were excluded and the rationale was documented in the Covidence Systematic Review Software to facilitate ease of tracking and reporting.

\section{Data extraction}

Data extraction forms were developed to provide a standardized and transparent method for examining the methodology and findings from the studies [38]. The forms were piloted on a subset of relevant papers that were included in the review and refined to ensure the extraction template met the specific objectives of the review. The following general characteristics were extracted: year of publication; title, aim, study design, country of conduct; number of frail and/or seriously ill patients engaged in research; patient condition with regard to reports of serious illness and/or frailty of patients. Engagement in research was extracted on four components: a) stages of the research cycle and associated activities within those stages; b) the level of engagement in the decision-making process, i.e., involvement, collaboration, and empowerment (see Table 1); c) barriers and facilitators to engaging frail and/or seriously ill patients in research; d) the described impacts of engaging frail and/or seriously ill patients. Data were extracted by two independent reviewers (CL, JL) and discrepancies resolved through discussion. A third party (DS) was available in the event that consensus could not be reached.

\section{Data analyses}

Narrative descriptions were reported for all studies. Data were synthesized in accordance with the guiding conceptual framework, i.e., engagement during the research cycle and by level of engagement. No meta-analyses were conducted as the aim was to identify the scope and types of patient engagement. Additionally, the heterogeneity across studies regarding the design, patient populations, methods, measures used, and a lack of numeric outcomes reported inhibited meta-analyses.

\section{Quality assessment}

Two independent reviewers (CL, JL) critically appraised included studies using the updated Mixed Methods Appraisal Tool (MMAT) [39]. The MMAT has been content validated, tested for inter-rater reliability and is increasingly utilized in the quality appraisal of systematic reviews of mixed studies [40-43]. Scores are based on criteria, which differ according to study type. Each study was appraised according to the criteria met and were ranked as having low, moderate, or high quality. But they were not excluded on the basis of low quality because the overall aim was to identify the scope and types of patient engagement. Reviewers resolved discrepancies through discussion and consensus.

\section{Results}

\section{Search and selection results}

There were 14,062 citations retrieved from electronic searching (see Fig. 1) [44]. After removing duplicates, 8763 original articles were screened, 431 full text reports were reviewed for eligibility, and 28 studies plus two additional studies identified through manual screening of reference lists in the included studies for a total of 30 studies met eligibility criteria. Included studies were published between 2006 and 2019, with a trend of increasing publications over time; $73 \%$ of studies were published within the last 5 years since 2014 (see Fig. 2).

\section{Characteristics of included studies}

Of 30 studies, 20 used qualitative methods (67\%), 2 used quantitative methods (7\%), and 8 used mixed methods (27\%) (see Table 3). All studies were published in English. Studies originated from: United Kingdom $(n=$ 18 studies), Canada $(n=5)$, Denmark $(n=3)$, United States $(n=2)$, the Netherlands $(n=1)$, and Malawi $(n=1)$.

The number of patients in the studies ranged from one [64] to 168 [68] with a median of 16 patients. There were 11 (37\%) studies where patients were engaged as a group with caregivers and/or other stakeholders (e.g., ex-patients, survivors, patient representatives/ advocates, or members of the public) $[7,24,46,52,53,57-61,72]$.

\section{Characteristics of patients in included studies}

Of 30 studies, 18 (60\%) included patients with specific cancer diseases: 10 heterogeneous cancers, 2 blood cancers, 2 head and neck cancers, 2 breast cancer, one kidney cancer, and one mesothelioma (see Table 4). Other studies included patients/persons with dementia $(n=6)$, older adults with frailty $(n=3)$, and palliative patients including malignant and non-malignant disease $(n=3)$. Patient characteristics of frailty and/or serious illness were 


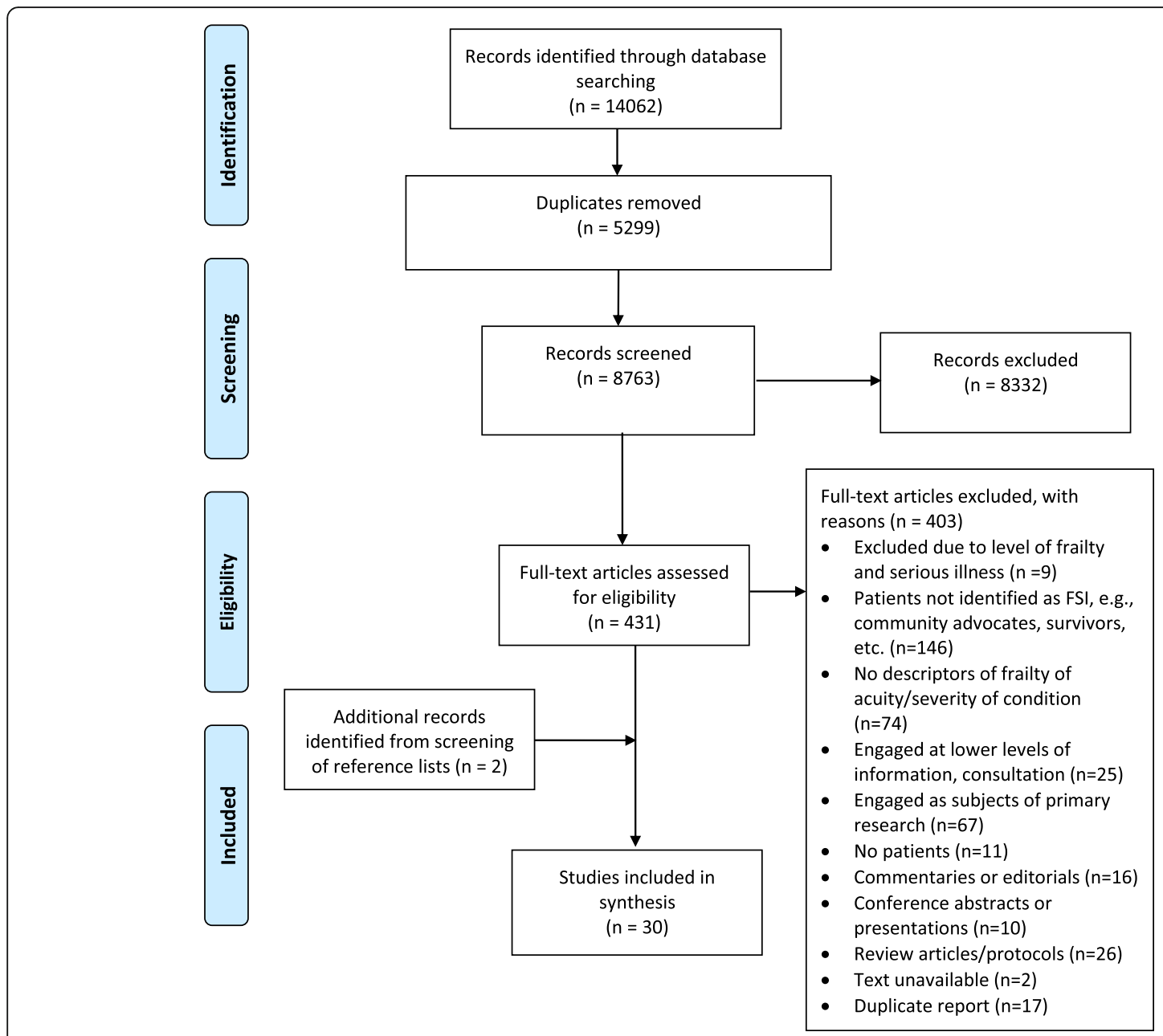

Fig. 1 PRISMA Flow Diagram

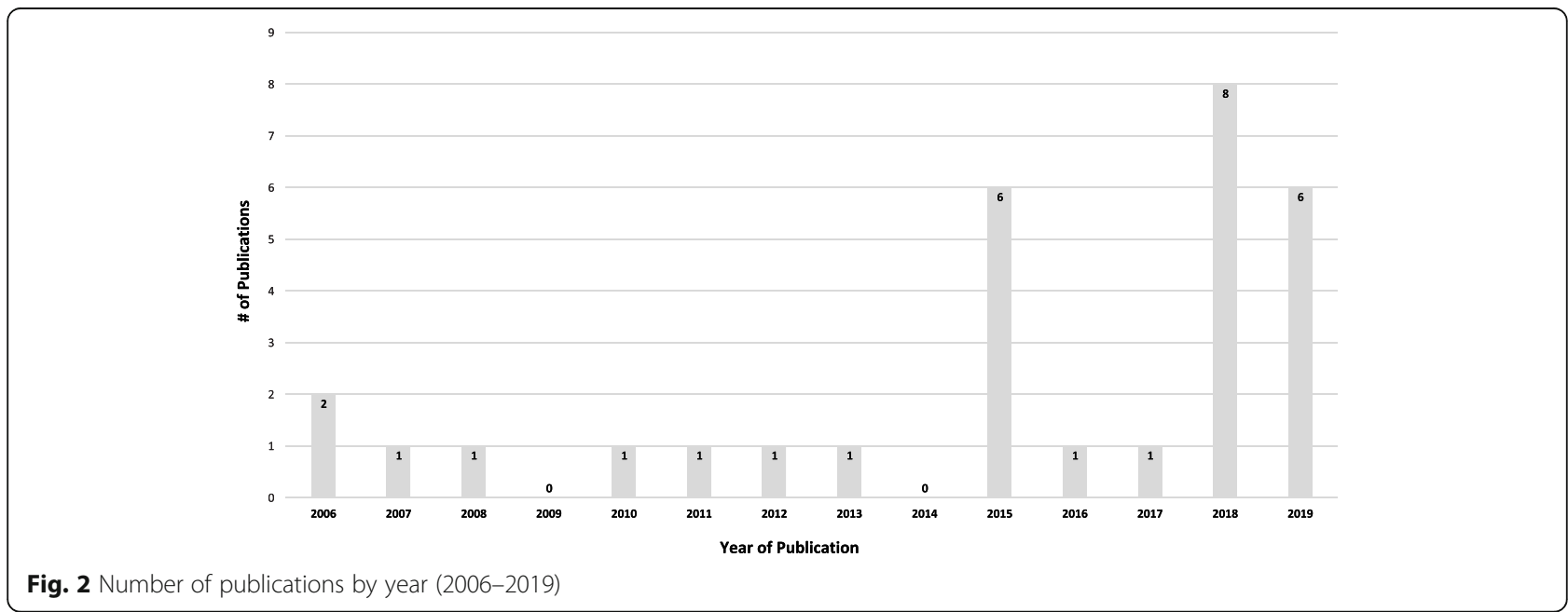

Fig. 2 Number of publications by year (2006-2019) 
Table 3 Characteristics of included studies

\begin{tabular}{|c|c|c|c|}
\hline $\begin{array}{l}\text { Author, year, country of } \\
\text { origin }\end{array}$ & $\begin{array}{l}\text { Study objective related to this systematic } \\
\text { review (from text) }\end{array}$ & $\begin{array}{l}\text { Methodological approach } \\
\text { and data collection }\end{array}$ & \# FSI patients engaged \\
\hline $\begin{array}{l}\text { Absolom } 2015 \text { [45] } \\
\text { UK }\end{array}$ & $\begin{array}{l}\text { To provide an overview of how research } \\
\text { collaborations with patient representatives } \\
\text { have developed over time and how patient } \\
\text { involvement has played a crucial role the }\end{array}$ & Qualitative; case study & $\begin{array}{l}14 \text { patients on treatment, } \\
\text { cancer survivors } \\
2 \text { additional patients on } \\
\text { research S/C }\end{array}$ \\
\hline
\end{tabular}

Arain 2015 [46]

UK

Bates 2018 [47]

Malawi

Bethell 2018 [48]

Canada

Bethell 2019 [49]

Canada

Burns 2018 [50]

US

Caldon 2010 [51]

UK

Chiu 2013 [7]

Canada

Collins 2015 [24]

UK

Corner 2007 [52]

UK

Cotterell 2011 [53]

UK

Davis 2019 [54]

UK

Froggatt 2015 [55]

UK

Heaven 2016 [56]

UK

Iwata 2019 [57]

US

Jones 2017 [58]

Canada success of local and national cancer research programs (eRapid study).

To explore different ways of involving consumers in cancer research in one regional network.

To report on experiences and lessons learnt using Photovoice in Blantyre, Malawi to encourage its wider use in research and practice.

To engage persons with dementia, friends, family, caregivers, and health and social care providers to identify and prioritize their questions for research related to living with dementia and prevention, diagnosis, and treatment of dementia.

To engage people with lived or clinical experience of frailty and produce a list of research priorities related to care, support, and treatment of older adults living with frailty

To report outcomes of engaging patients and caregivers, identification of knowledge gaps, and prioritization of high impact research questions or recommendations related to hematopoietic cell transplantation.

To report on the process and consequences of consumer participation, rather than the findings of the illustrative (primary) research study

To share the experience of engaging cancer patients/ survivors in a participatory research study.

To outline the challenges faced by the North Trent Cancer Research Network Consumer Research Panel model of Public \& Patient Involvement.

To involve cancer patients across the UK in identifying priorities for research investment.

To explore the personal impact of involvement on the lives of service users affected by cancer.

To consult frail older adults about services improvements and research topics associated with the design and delivery of discharge from hospital. To use successive PPIE processes to enable a permanent PPIE panel to be established.

To describe the experiences of people's participation in patient and public involvement (PPI) in supportive and palliative care research.

To create a structure to enable meaningful, sustainable public involvement within the $\mathrm{cmRCT}$ framework.

To describe the benefits of patient-driven research in the field of head and neck oncology, review lessons learned from establishing partnerships with patients and caregivers and serve as a model for further patient-driven research endeavors.

To identify research priorities in the management of kidney cancer.

To report on the process of having current and
Quantitative; descriptive

Qualitative; participatory action research (PAR)

Mixed methods; James Lind Alliance Research Priority Setting Partnership (PSP) methods

Mixed methods; James Lind Alliance Research Priority Setting Partnership (PSP) methods

Qualitative; focus groups

Qualitative; case study

Mixed methods; participatory action research (PAR)

Qualitative; case study

Qualitative; participatory action research \& nominal group study

Qualitative; focus groups

Qualitative; focus groups and interviews

Qualitative; semi-structured interviews

Qualitative; case study

Qualitative; case study

Mixed methods; James Lind Alliance Research Priority Setting Partnership (PSP) methods

Qualitative; case study
15 patients on treatment, ex-patients, cancer survivors, caregivers

6 patients with palliative care needs

7 persons with dementia 1 additional person with dementia on research S/C

52 initial survey 6 interim prioritization \# $\mathrm{n} / \mathrm{r}$ for research $\mathrm{S} / \mathrm{C}$ participation

25 patients

Patients also served on steering committee \& working groups

2 patients

18 patients on treatment, ex-patients, cancer survivors

38 patients on treatment ex-patients, cancer survivors

130 patients on treatment, ex-patients/cancer survivors

64 patients on treatment, ex-patients/cancer survivors

27 frail older adults

8 patients

1 patient on research S/C

70 frail older adults

15 patients on treatment, ex-patients, cancer survivors

34 patients on treatment: 34 waiting surgery: 7 on research S/C (conflated with caregivers)

8 patients on treatment, 
Table 3 Characteristics of included studies (Continued)

\begin{tabular}{|c|c|c|c|}
\hline $\begin{array}{l}\text { Author, year, country of } \\
\text { origin }\end{array}$ & $\begin{array}{l}\text { Study objective related to this systematic } \\
\text { review (from text) }\end{array}$ & $\begin{array}{l}\text { Methodological approach } \\
\text { and data collection }\end{array}$ & \# FSI patients engaged \\
\hline Denmark & former cancer patients involved as co-researchers. & & ex-patients, cancer survivors \\
\hline $\begin{array}{l}\text { Jorgensen } 2018 \text { [60] } \\
\text { Denmark }\end{array}$ & $\begin{array}{l}\text { To investigate the impact of involving patient } \\
\text { representatives as peer interviewers in a research } \\
\text { project on patient empowerment. }\end{array}$ & $\begin{array}{l}\text { Mixed methods; qualitative \& } \\
\text { quantitative analyses }\end{array}$ & $\begin{array}{l}16 \text { patients on treatment, } \\
\text { ex-patients, cancer survivors }\end{array}$ \\
\hline $\begin{array}{l}\text { Lechelt } 2018 \text { [61] } \\
\text { Canada }\end{array}$ & $\begin{array}{l}\text { To determine research priorities for patients with } \\
\text { head and neck cancer. }\end{array}$ & $\begin{array}{l}\text { Mixed methods (James Lind } \\
\text { Alliance method for PSP) }\end{array}$ & $\begin{array}{l}104 \text { patients on treatment, } \\
\text { ex-patients, cancer survivors } \\
5 \text { patients on research S/C }\end{array}$ \\
\hline $\begin{array}{l}\text { Litherland } 2018 \text { [62] } \\
\text { UK }\end{array}$ & $\begin{array}{l}\text { To describe the involvement of people with } \\
\text { dementia and carers as part of the IDEAL study }\end{array}$ & Qualitative; case study & 3 persons with dementia \\
\hline $\begin{array}{l}\text { Littlechild } 2015 \text { [63] } \\
\text { UK }\end{array}$ & $\begin{array}{l}\text { To evaluate the impact of working with co-researchers } \\
\text { from the perspective of multiple stakeholders on a } \\
\text { project in which older people with dementia and older } \\
\text { people from a black and minority ethnic community } \\
\text { were involved as co-researchers. }\end{array}$ & Qualitative; case study & $\begin{array}{l}11 \text { older persons with } \\
\text { dementia and/or frailty }\end{array}$ \\
\hline $\begin{array}{l}\text { Parveen } 2018 \text { [64] } \\
\text { UK }\end{array}$ & $\begin{array}{l}\text { To report the process of involving a diverse range of } \\
\text { experts-by-experience approach within the Caregiving } \\
\text { HOPE study, and its impact on research processes and } \\
\text { outcomes. }\end{array}$ & Qualitative; case study & 1 older person with dementia \\
\hline $\begin{array}{l}\text { Perkins } 2008[65] \\
\text { UK }\end{array}$ & $\begin{array}{l}\text { To determine patients' priorities for palliative care } \\
\text { research through a questionnaire study }\end{array}$ & Quantitative; survey & $\begin{array}{l}19 \text { patients } \\
10 \text { patients piloted tool }\end{array}$ \\
\hline $\begin{array}{l}\text { Piil } 2019 \text { [66] } \\
\text { Denmark }\end{array}$ & $\begin{array}{l}\text { To identify future research agendas that reflect the } \\
\text { concerns and unexplored areas of interest for patients } \\
\text { with life-threatening cancer, their relatives and the } \\
\text { clinical specialists during the cancer trajectory. }\end{array}$ & Qualitative; focus groups & $\begin{array}{l}6 \text { patients } \\
2 \text { patients on research } \mathrm{S} / \mathrm{C}\end{array}$ \\
\hline $\begin{array}{l}\text { Schölvinck } 2019 \text { [67] } \\
\text { The Netherlands }\end{array}$ & $\begin{array}{l}\text { To identify and prioritize research needs of } \\
\text { hematological cancer patients and people who have } \\
\text { undergone a stem cell transplantation. }\end{array}$ & $\begin{array}{l}\text { Mixed methods; focus groups, } \\
\text { interviews, questionnaire }\end{array}$ & $\begin{array}{l}19 \text { patients interviewed } \\
27 \text { patients in focus group } \\
146 \text { patients surveyed } \\
3 \text { patients on research S/C }\end{array}$ \\
\hline $\begin{array}{l}\text { Stephens } 2015 \text { [68] } \\
\text { UK }\end{array}$ & $\begin{array}{l}\text { To identify top } 10 \text { research priorities relating to } \\
\text { mesothelioma, and identify those unanswered } \\
\text { questions that involved an intervention, in order to } \\
\text { aid translation into answerable research questions. }\end{array}$ & $\begin{array}{l}\text { Mixed methods; James Lind } \\
\text { Alliance Research Priority Setting } \\
\text { Partnership (PSP) methods }\end{array}$ & $\begin{array}{l}168 \text { patients surveyed } \\
6 \text { patients at consensus } \\
\text { meeting }\end{array}$ \\
\hline $\begin{array}{l}\text { Stevenson } 2019[69] \\
\text { UK }\end{array}$ & $\begin{array}{l}\text { To involve individuals with dementia as co-researchers } \\
\text { in analysis of research findings to enhance validity } \\
\text { through a process of applying multiple perspectives } \\
\text { to data analysis. }\end{array}$ & Qualitative; case study & 4 persons with dementia \\
\hline $\begin{array}{l}\text { Tanner } 2012[70] \\
\text { UK }\end{array}$ & $\begin{array}{l}\text { To report on the process of involving older people } \\
\text { with dementia in all stages of the research process. }\end{array}$ & Qualitative; case study & 3 persons with dementia \\
\hline $\begin{array}{l}\text { Wright } 2006[71] \\
\text { UK }\end{array}$ & $\begin{array}{l}\text { To provide detail of collaborative participation of } \\
\text { patients and carers in the design and conduct of } \\
\text { participatory research study in setting the cancer } \\
\text { research agenda. }\end{array}$ & Qualitative; participatory approach & 22 patients \& caregivers \\
\hline $\begin{array}{l}\text { Wright } 2006[72] \\
\text { UK }\end{array}$ & $\begin{array}{l}\text { To describe the experiences of involving palliative } \\
\text { care patients as co-researchers in end of life research. }\end{array}$ & Qualitative; case study & 15 patients \\
\hline
\end{tabular}

mostly reported in relation to: receipt of active treatment(s) associated with high symptom burden $(n=18)$, receipt of palliative or end-of-life care $(n=3)$, higher levels of cognitive impairment $(n=6)$, and physical frailty associated with old age $(n=3)$.

Of 30 studies, $12(40 \%)$ reported the ages of the patient-partners $[24,45,52,55-57,61,65-67,69,70]$ and six $(6 / 12)$ of them also included patients 75 years of age and above $[24,55,56,67,69,70]$. Five of 30 studies (17\%) reported on ethnicity $[46,53,54,57,63]$; three (3/
5) of which reported ethnicity more broadly in terms of "diversity" [46, 53, 63].

\section{Patient partner research roles: research stages and activities}

No studies reported engagement of frail and/or seriously ill patients at the level of empowerment, i.e., the provision of primary direction and governance to a given research endeavor. The highest level of engagement was reported in four of 30 studies (13\%) where collaboration 


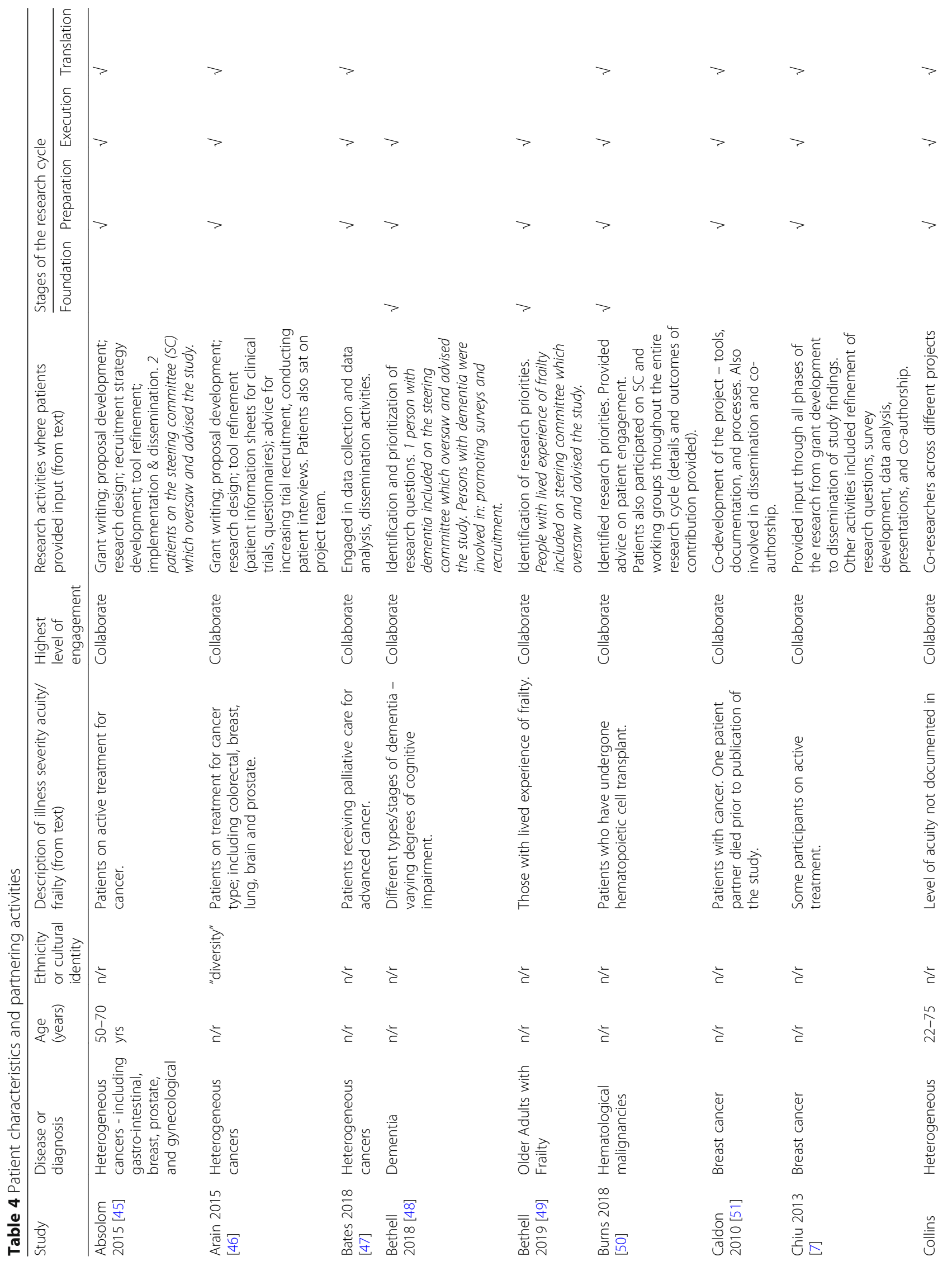




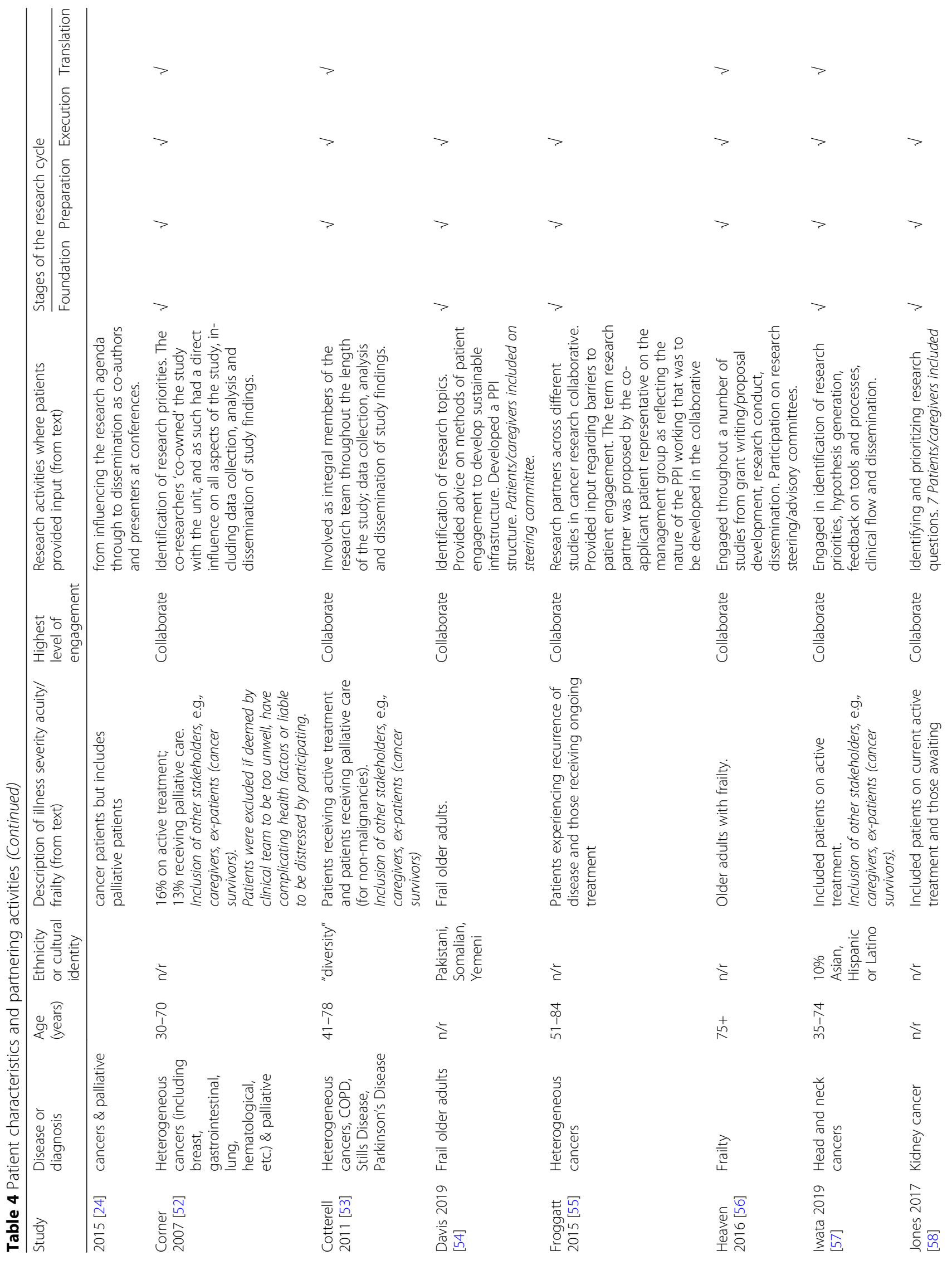




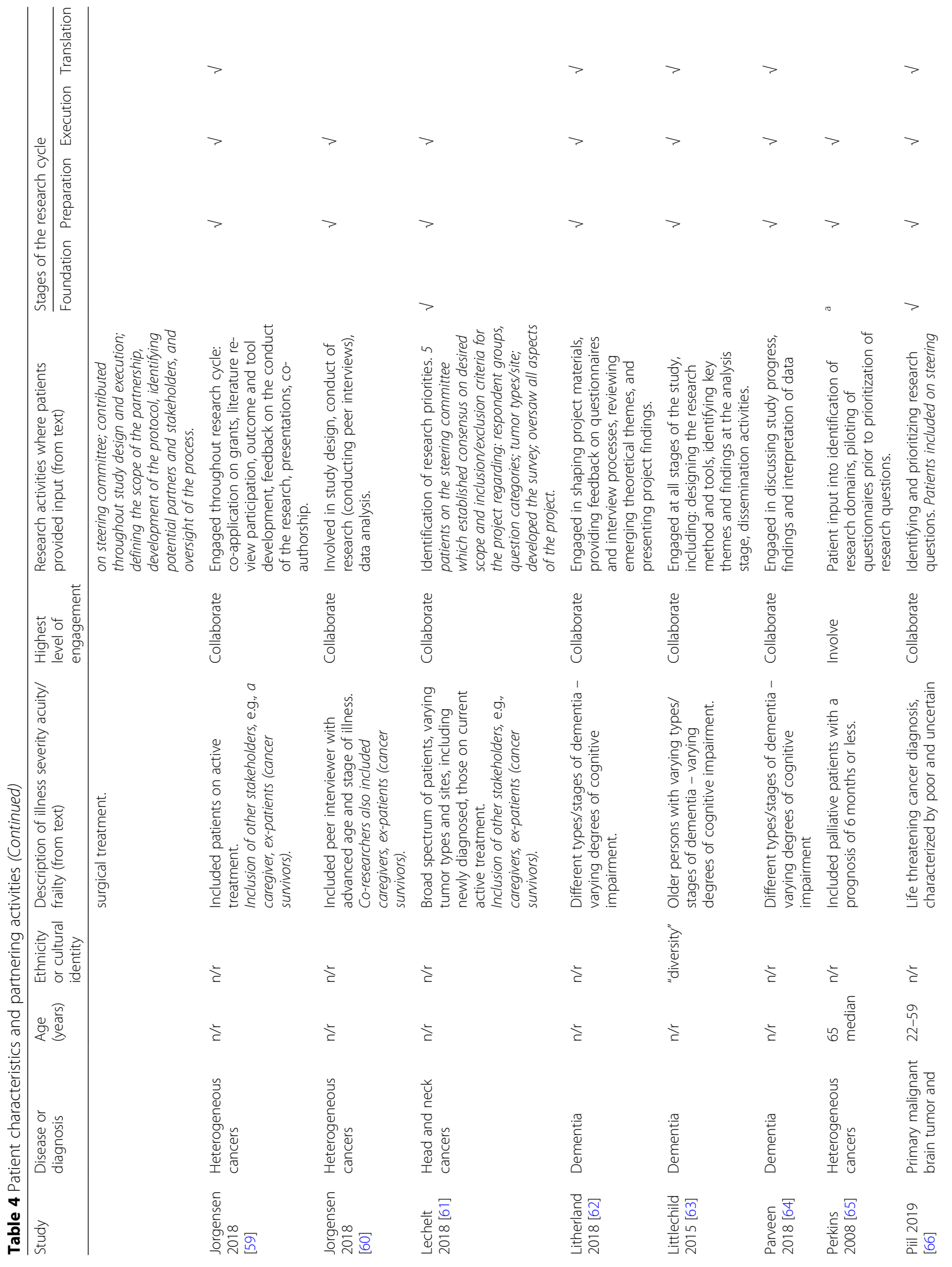




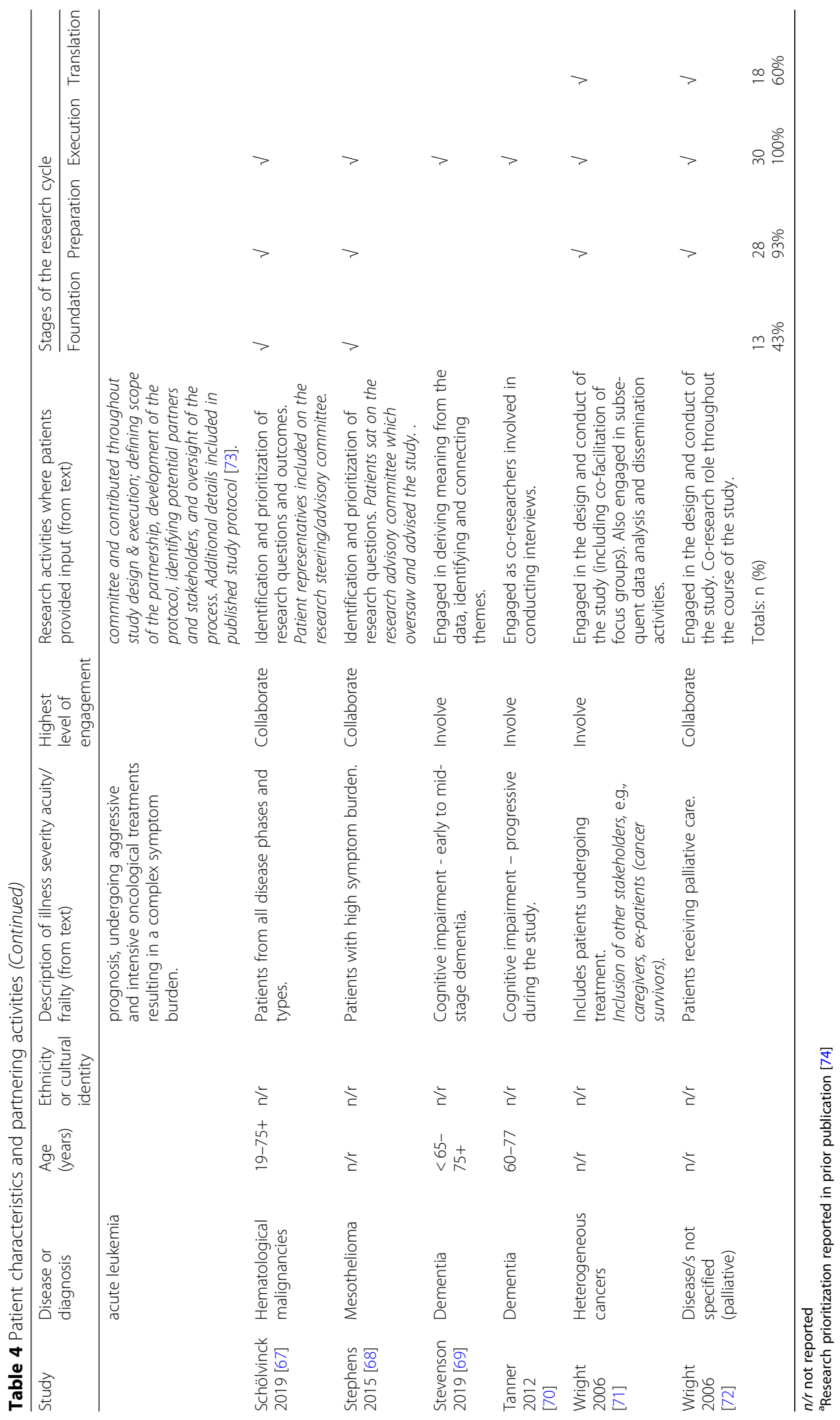


was demonstrated across all four stages of the research cycle (see Table 4). Patients in these studies partnered in activities including, but not limited to: delineation of the scope of the partnership, contribution to study design, co-leadership on working groups during study execution, data analysis, dissemination activities, and adoption of decision-making roles on research steering/advisory committees [50, 52, 57, 66].

Seven studies (23\%) included patients in research priority setting at the broader level of biomedical specialty/ disease/condition, rather than at the individual study level $[48,49,54,58,61,67,68]$. These studies included patients who were representative of the condition as partners on research steering/advisory committees and who contributed to shared decision-making across the research study cycle.

Eleven studies (37\%) described collaboration with frail and/or seriously ill patients across the latter three stages of the research cycle (preparation, execution, and translation) at the individual study level $[7,45,47,51,53,59$, $62-64,71,72]$. Patients partnered in a variety of different activities that mostly included: assistance with grant applications, input into study design, co-design of project materials, recruitment strategies, data analysis, dissemination activities, and decision-making at research steering/advisory committees. Four (13\%) studies included frail and/or seriously ill patient partners from research collaboratives or networks who assisted with the identification of appropriate patient engagement strategies specific to frail and/or seriously ill populations at a broader system level. Patients described contributing to grant writing, proposal development, tool refinement, conducting interviews, representing research findings, and co-authorship on papers across different studies [24, 46, 55, 56].

Four studies (13\%) described patient roles during key stages of the research process, rather than across the research cycle $[60,65,69,70]$. Patients participated in activities at the execution stage of the research cycle, where they piloted research tools, served as peer interviewers, assisted in other forms of data collection, or interpreted data sets $[60,65,69,70]$.

\section{Barriers and facilitators to partnering with patients System level factors}

The most commonly cited barrier for researchers to partner in research with frail and/or seriously ill patients was resource constraints, including financial concerns, human resource capacity for support, and the time commitment required for meaningful engagement $(15 / 30)[7,24,45-47,54,56,59,60,62-$ 64, 69, 71, 72] (see Fig. 3). Researchers also cited lack of formal infrastructure and policy, poorly defined governance mechanisms, and inconsistent processes to support meaningful patient partnerships as a system level barrier $(4 / 30)[24,53,59,64]$.

Both patients and researchers reported the need to establish consistent, formal compensation frameworks in order to recognize patient contribution and reimburse patients for their time, travel, and incidental costs (11/30) [7, 45-47, 56, 59, 61-64, 66]. Researchers' stressed the importance of having a rigorous macro and micro level infrastructure with appropriate policy and governance mechanisms to support successful and meaningful patient partnership beyond a singular study $(11 / 30)[24,46,48,53,54,56,57,59,64,69$, 72]. Relatedly, studies made direct reference to the significance of ensuring that funding for patient engagement is integrated into the research structure in order to facilitate and sustain patient engagement activities $(8 / 30)[24,45,46,54,59,62,64,69]$.

\section{Team level factors}

Lack of role clarity and expectations related to the contribution of patients throughout the research cycle was cited as a barrier to meaningful engagement by both patients and researchers (6/30) (see Fig. 3) [24, 45, 53, 59, 63, 69].

The most commonly cited facilitator to meaningful engagement with frail and/or seriously ill patients as partners in research was to establish a collaborative team environment built on trust, mutual respect, and openness $(18 / 30)[7,24,45,47,51,53,57,59$, $60,62-64,66,67,69-72]$. Researchers also stressed the importance of promoting structural accessibility as a facilitator to meaningful engagement, with an emphasis on inclusivity and diversity of representation (i.e., ensuring that patient partners were representative of varied ethnocultural and socioeconomic groups) (17/30) [7, 24, 45, 47-49, 52, 53, 56, 57, 59, $62-64,68,71,72]$. The importance of regular contact, ongoing support, feedback, and team de-briefing was recognized as a requirement to effective partnership for both patients and researchers $(15 / 30)[7,24$, $45,47,51,53,54,57,59,60,62,64,67,70,72]$. Flexibility in the timing, methods and modes of contribution (13/30) $[7,45,50,53,54,59,62-65,69$, $70,72]$, clarity in roles and the expected contribution of patients throughout the partnership (10/30) $[24,45,46,51,53,55,57,59,60,69]$, and clear and transparent processes for all members of the team $(9 / 30)[24,50-52,59,60,63,64,70]$ were cited by both patients and researchers as key facilitators to the process. Facilitating communication through provision of multiple mechanisms for input and feedback, and limiting overly technocratic jargon was also perceived as vital to enabling patients' contribution $(9 / 30)[7,24,45,51,55,57,61,68,70]$. 


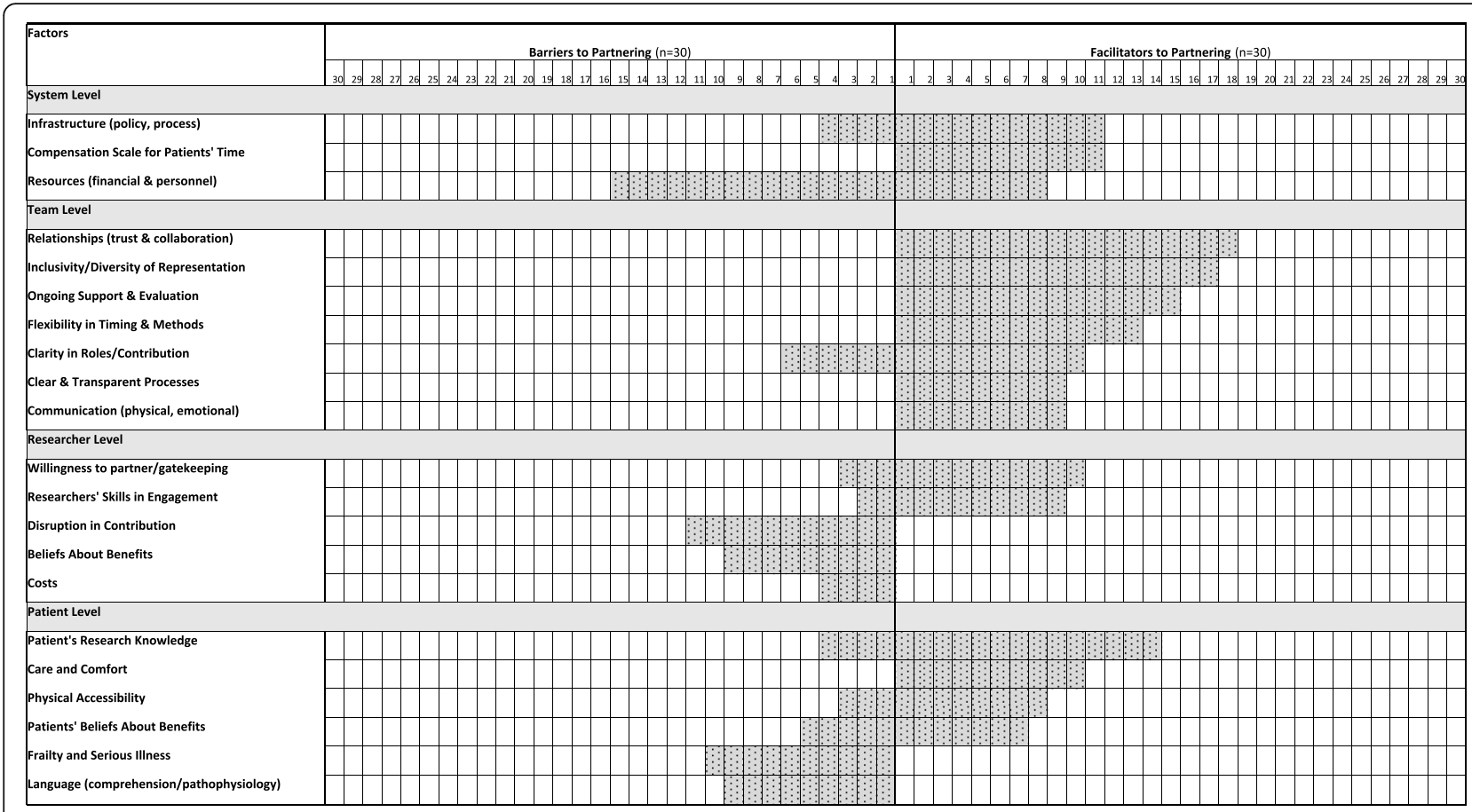

Fig. 3 Themes and sub-themes of barriers and facilitators to partnering with frail and/or seriously ill patients

\section{Researcher level factors}

The most commonly cited perceived barrier of researchers to partnering with frail and/or seriously ill patients in research was related to their concerns about patients' potential lack of continuity in contributions throughout the research cycle due to deterioration in patients' health or cognition, or death $(11 / 30)$ (see Fig. 3) [7, 45, 47, 53, 55, 57, 59, 61, 68, 70, 72]. The second most common barrier was researchers' uncertainty about the value or overall benefit of patient engagement, particularly given the outcomes of the partnership on research may not be visible for some time $(9 / 30)$ [24, 46, 52, 53, 56, 57, 62, 69, 72]. Other researcher barriers were perception that research outputs identified by patient partners may not be fully aligned with the initial objectives of the project or might be too costly to implement $(4 / 30)$ [24, $60,63,67]$, concern for placing additional or perceived unnecessary burden on patients $(3 / 30)$ [47, 52, 65], and lack of familiarity and confidence in patient engagement, particularly where patients assume a partnership role $(2 / 30)[56,62]$.

Facilitators were researchers' willingness to share decision-making with patients as essential to partnering with patients $(10 / 30)[7,24,48,50,51,53,56$, 59-61]. Another facilitator was researchers' knowledge and expertise of patient engagement practices as vital to mitigating potential harms of engagement $(9 / 30)$ [7, $24,47,51,54,57,59,62,66]$.

\section{Patient level factors}

The most common patient level barrier was being frail and/or experiencing severe illness or limited cognitive status (10/30) [47-49, 52, 65, 66, 68, 70-72] (see Fig. 3). The second most common barrier was communication difficulties due to diminished capacity for comprehension, heightened emotional distress due to subject matter material, or pathophysiology (9/30) [24, 48, 55-57, $65,67,68,70]$. Other barriers were patients' apprehension about the impact of their engagement and their capacity to influence action and outcomes of the research process $(5 / 30)[53,55,57,62,68]$, perceived reservations about the extent to which patient partners possess the requisite knowledge and skills for research $(4 / 30)[24,60,63,69]$, and limited accessibility and concerns related to patients' potential difficulty to physically attend meetings $(3 / 30)[7,54,57]$.

Skills building by providing basic training for patients in research methods and research ethics, was cited by both patients and researchers as a key facilitator to building confidence in contribution and partnership (14/30) [7, 45-47, $51,56,57,59,60,63,69-72]$. Another facilitator for engagement was the provision of practical and emotional support, and comfort (e.g., refreshments, quiet spaces) (10/30) [7, 47, 53, 57, 61, 62, 64, 69, 70, 72]. Other facilitators for patients were ensuring physical accessibility to meeting spaces $(8 / 30)[7,47,54,62,64,69,70,72]$, and patients' altruistic beliefs that their involvement would improve care and outcomes for others $(7 / 30)[45,51,53,54,57,59,63]$. 


\section{Impacts}

\section{Perceived impact on patients}

The most commonly cited positive impact to partnering in research was described by patients as a renewed sense of personal agency in the face of debilitating disease and loss of self-esteem $(11 / 30)$ [7, 45, 47, 51, 53-55, 62, 63, $69,70]$ (see Table 5). Patients also described positive impacts stemming from relationships formed with other patients and members of the research team which appeared to provide additional emotional support in their illness journey $(11 / 30)$ [7, 51, 53, 55, 57, 62-64, 66, 69, 70]. Patient partnership was cited as having a positive beneficial impact for patients in relation to incorporation of their priorities for research questions and meaningful outcomes (10/30) [7, 24, 50, 51, 54, 56, 57, 61, 65, 67]. The development of new skills and knowledge (8/30) $[45,51,55,59,60,62,63,71]$ and acquisition of knowledge about their own disease/condition were also perceived by patients to be positive personal impacts $(3 / 30)$ [51, 55, 69].

Perceived negative impacts for patients were cited as potential physical and/or cognitive fatigue related to the effort required during engagement $(5 / 30)$ [7, 47, 53, 55, $72]$. Increased emotional vulnerability and the potential for distress in reliving their illness and related negative experiences were also cited as perceived negative impacts to patient as partners $(5 / 30)[7,47,55,71,72]$.

\section{Perceived impacts on researchers}

Perceived positive impacts of partnering with frail and/ or seriously ill patients in the research process were cited as increasing researchers' awareness, and sensitizing them to the lived experience of illness and suffering $(17 / 30)$ [7, 45, 47, 50-52, 54, 55, 57, 59, 62, 63, 66, 67, 69, 70, 72]. Partnering with patients was reported to challenge negative or ambiguous views held by researchers about the utility of patient engagement (7/30) $[52,59,62,63,65,71,72]$. The potential to enhance interpersonal skills and promote inter-disciplinary collaboration (4/30) were also cited as positive impacts to researchers engaging frail and/or seriously ill patients as partners in research $[51,59,62,63]$.

The negative impacts described by researchers engaging frail and/or seriously ill patients as partners in research were described in relation to the potential strain on scarce resources (particularly related to funding and the human resource capacity required to support patient engagement activities) (15/30) [7, 24, 45-47, 54, 56, 59, $60,62-64,69-71]$. The additional complexity of the process and time required for engaging patient partners was also cited as a potential impediment to advancing project objectives and meeting timelines closely aligned with research funding cycles $(2 / 30)$ [7, 64].

\section{Perceived impact on the research}

Researchers partnering with frail and/or seriously ill patients cited positive impacts on the research itself, with the design, execution and end of grant translation of research perceived as more applicable to those populations for whom the research is intended to serve (13/30) [7, $51,54-56,59,62-64,69-72]$. On a more tangible level, including patients in the research process was also described as having a positive impact on the development of research tools (e.g., consent and data collection tools), processes (e.g., recruitment and retention), and methods that were more appropriate for use with frail and/or seriously ill patients $(13 / 30)[7,45-47,51,56,57,59$, $62-64,70,71]$. Research produced with patient partners was also perceived to incorporate outcomes more relevant for frail and/or seriously ill populations (11/30) [46, $50,51,54,63,64,66,69-72]$, and generated new ideas and direction for researchers and funders (11/30) [24, $45,48,49,51,52,57,61,65,67,68]$. Research produced with patients is also perceived to produce outputs that are more accessible to patients $(9 / 30)[24,45,47,51,52,56$, $57,64,69]$, was more reflective of the lived experience of illness, frailty, and/or treatment impacts (6/30) [24, 48, 49, $52,58,61]$; facilitated democratization of the allocation of scarce funds $(2 / 30)[49,52]$, and increased transparency and accountability for public funds (1/30) [55].

\section{Study quality}

All 30 studies provided evidence of relevant sources of data appropriate for the research question and used a research design relevant to address the research question. Of the 20 qualitative studies (66\%) in the review, most were rated as high quality using the MMAT [47, 50, 52, $53,55,57,59,63,66,69-72]$. Seven $(7 / 20)$ of the qualitative studies were rated moderately lower because it was difficult to determine whether interpretation of the results was sufficiently substantiated by data $[24,45,51$, $54,56,62,64]$. For the two quantitative studies (6.7\%) $[46,65]$, there was a risk of nonresponse bias in both studies, particularly in one study where those deemed too ill were excluded from the opportunity to participate [65]. For the eight mixed methods studies (26.7\%) [7, 48, $49,58,60,61,67,68]$, five had risk of nonresponse bias $[48,49,58,61,67]$ and three reported interpretation of the qualitative results that was not sufficiently substantiated by the data $[48,61,68]$ (see Table 6).

\section{Discussion}

The overall aim of this review was to synthesize the evidence on the engagement of frail and/or seriously ill patients as research partners across the research cycle. The 30 studies included in the review provide an indication of an upward trend in the inclusion of frail and/or seriously ill patients as partners in research over the past 
Table 5 Impacts of Patient Engagement ( $N=30$ studies)

\author{
Patient Level -Perceived Impacts \\ Positive Impacts \\ 11 (37\%) Renewed sense of purpose/agency \\ $[7,45,47,51,53-55,62,63,69,70]$ \\ 11 (37\%) Emotional/peer support [7, 51, 53, 55, 57, 62-64, 66, 69, 70] \\ 10 (33\%) Incorporation of patients' priorities for research and \\ outcomes $[7,24,50,51,54,56,57,61,65,67]$ \\ 8 (27\%) Develop new knowledge and skills $[45,51,55,59,60,62,63,71]$ \\ $3(10 \%)$ Acquire insights into disease and treatment $[51,55,69]$ \\ Researcher - Perceived Impacts

\section{Positive Impacts} \\ 17 (57\%) Sensitizes researchers to experiential knowledge not gained \\ at the bench or the bedside. Recognizing \\ human experience $[7,45,47,50-52,54,55,57,59,62,63,66,67,69,70,72]$ \\ 7 (23\%) Challenges negative/ambiguous beliefs and perceptions of utility \\ of patient partnerships $[52,59,62,63,65,71,72]$ \\ 4 (13\%) Increase interpersonal skills and highlighted significance of \\ partnerships in research $[51,59,62,63]$
}

\title{
Research Level - Perceived Impacts
}

\section{Positive Impacts}

13 (43\%) Improves/informs research design, execution, and translation [7, 51, 54-56, 59, 62-64, 69-72]

13 (43\%) Research tools (e.g., consent and data collection form), processes (e.g., recruitment and retention), and methods are more relevant $[7,45-47,51,56,57,59,62-64,70,71]$

11 (37\%) Outcomes are identified as being more relevant to patients $[46,50,51,54,63,64,66,69-72]$

11 (33\%) Patients' input offers directions for researchers and research

funding agencies - generation of new ideas $[24,45,48,49,51,52,57,61,65,67,68]$

9 (30\%) Research outputs are more accessible to the public

$[24,45,47,51,52,56,57,64,69]$

$6(20 \%)$ Research priorities ranked by patients reflect applicability to the lived experience of illness, frailty, and/or treatment $[24,48,49,52,58,61]$

2 (7\%) Democratization of allocation of research resources [49, 52]

1 (3\%) Increased transparency and accountability for publicly-funded research [55]

decade, with a marked increase in the number of studies in the past 5 years. Most studies included patients with cancer, with fewer studies partnered with patients who had dementia and/or frailty, or patients with palliative care needs. There was evidence of research partnerships with frail and/or seriously ill patients across the research cycle. These activities engaged patients on research related to setting priorities, selecting outcomes considered important to patients, grant review, tool development, research conduct, and dissemination of findings. These findings lead to the following three key points for discussion.
Negative Impacts

$5(17 \%)$ Emotional vulnerability or emotional distress $[7,47,55,71,72]$

5 (17\%) Physical/cognitive fatigue $[7,47,53,55,72]$
15(50\%) Investment and expenditure of time and resources [7, 24, 45-47, 54, 56, 59, 60, 62-64, 69-71]

$2(7 \%)$ Complexity/intensity of the process may serve as an impediment to meeting project timeline $[7,64]$

Negative Impacts

\section{Barriers, facilitators and impacts to engaging frail and/or seriously ill patient in research}

The barriers and facilitators to partnering with frail and/ or seriously ill patients (e.g., funding, infrastructure, role clarity, capacity building for both patients and researchers, structural inclusivity, trust and willingness to collaborate) are similar to those reported in other systematic and scoping reviews of patient engagement $[2,12,22,28,75-77]$. When engaging frail and/or seriously ill patients as partners across the research cycle, the degree of illness and/or frailty, and potential instability in patients' health warrants more concern for 
Table 6 Quality appraisal results using MMAT [39]

\begin{tabular}{|c|c|c|c|c|c|c|c|c|c|c|c|c|c|c|c|c|c|}
\hline \multirow[t]{3}{*}{ MMAT Items } & \multirow{2}{*}{\multicolumn{2}{|c|}{$\begin{array}{l}\text { Screening } \\
\text { Questions }\end{array}$}} & \multicolumn{15}{|c|}{ Methodological Quality Criteria } \\
\hline & & & \multicolumn{5}{|c|}{ Qualitative Studies } & \multicolumn{5}{|c|}{ Quantitative Studies } & \multicolumn{5}{|c|}{ Mixed Methods } \\
\hline & 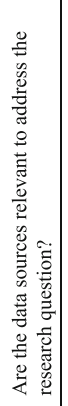 & 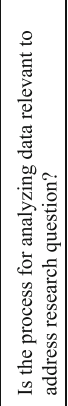 & 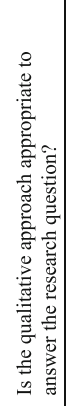 & 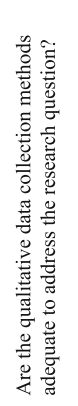 & 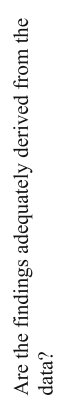 & 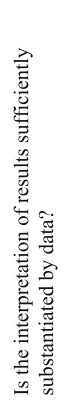 & 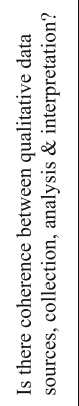 & 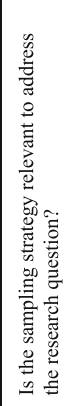 & 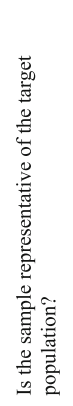 & 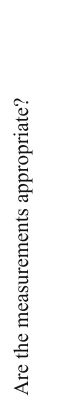 & 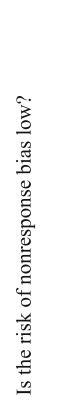 & 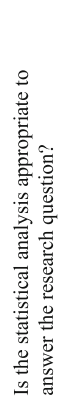 & 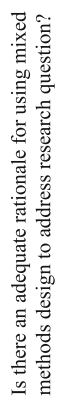 & 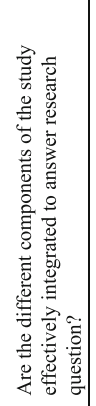 & 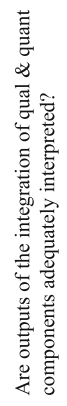 & 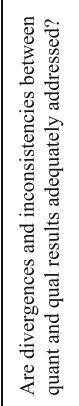 & 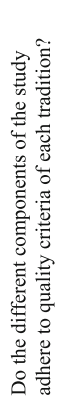 \\
\hline \multicolumn{18}{|c|}{ Qualitative Studies $(\mathrm{n}=\mathbf{2 0})$} \\
\hline Absolom 2015 [45] & $\mathrm{Y}$ & $\mathrm{Y}$ & $\mathrm{Y}$ & $\mathrm{Y}$ & $\mathrm{Y}$ & CT & $\mathrm{Y}$ & & & & & & & & & & \\
\hline Bates 2018 [47] & $\mathrm{Y}$ & $\mathrm{Y}$ & $\mathrm{Y}$ & $\mathrm{Y}$ & $\mathrm{Y}$ & $\mathrm{Y}$ & $\mathrm{Y}$ & & & & & & & & & & \\
\hline Burns 2018 [50] & $\mathrm{Y}$ & $\mathrm{Y}$ & $\mathrm{Y}$ & $\mathrm{Y}$ & $\mathrm{Y}$ & $\mathrm{Y}$ & $\mathrm{Y}$ & & & & & & & & & & \\
\hline Caldon $2010[51]$ & $\mathrm{Y}$ & $\mathrm{Y}$ & $\mathrm{Y}$ & $\mathrm{Y}$ & $\mathrm{Y}$ & CT & $\mathrm{Y}$ & & & & & & & & & & \\
\hline Collins 2015 [24] & $\mathrm{Y}$ & $\mathrm{Y}$ & $\mathrm{Y}$ & $\mathrm{Y}$ & CT & CT & $\mathrm{Y}$ & & & & & & & & & & \\
\hline Corner 2007 [52] & $\mathrm{Y}$ & $\mathrm{Y}$ & $\mathrm{Y}$ & $\mathrm{Y}$ & $\mathrm{Y}$ & $\mathrm{Y}$ & $\mathrm{Y}$ & & & & & & & & & & \\
\hline Cotterell 2011 [53] & $\mathrm{Y}$ & $\mathrm{Y}$ & $\mathrm{Y}$ & $\mathrm{Y}$ & $\mathrm{Y}$ & $\mathrm{Y}$ & $\mathrm{Y}$ & & & & & & & & & & \\
\hline Davis 2019 [54] & $\mathrm{Y}$ & $\mathrm{Y}$ & $\mathrm{Y}$ & $\mathrm{Y}$ & $\mathrm{Y}$ & CT & $\mathrm{Y}$ & & & & & & & & & & \\
\hline Froggatt 2015 [55] & $\mathrm{Y}$ & $\mathrm{Y}$ & $\mathrm{Y}$ & $\mathrm{Y}$ & $\mathrm{Y}$ & $\mathrm{Y}$ & $\mathrm{Y}$ & & & & & & & & & & \\
\hline Heaven 2016 [56] & $\mathrm{Y}$ & $\mathrm{Y}$ & $\mathrm{Y}$ & $\mathrm{Y}$ & $\mathrm{Y}$ & CT & $\mathrm{Y}$ & & & & & & & & & & \\
\hline Iwata 2019 [57] & $\mathrm{Y}$ & $\mathrm{Y}$ & $\mathrm{Y}$ & CT & $\mathrm{Y}$ & $\mathrm{Y}$ & $\mathrm{Y}$ & & & & & & & & & & \\
\hline Jorgensen 2018 [59] & $\mathrm{Y}$ & $\mathrm{Y}$ & $\mathrm{Y}$ & $\mathrm{Y}$ & $\mathrm{Y}$ & $\mathrm{Y}$ & $\mathrm{Y}$ & & & & & & & & & & \\
\hline Litherland 2018 [62] & $\mathrm{Y}$ & $\mathrm{Y}$ & $\mathrm{Y}$ & $\mathrm{Y}$ & $\mathrm{Y}$ & CT & $\mathrm{Y}$ & & & & & & & & & & \\
\hline Littlechild 2015 [63] & $\mathrm{Y}$ & $\mathrm{Y}$ & $\mathrm{Y}$ & $\mathrm{Y}$ & $\mathrm{Y}$ & $\mathrm{Y}$ & $\mathrm{Y}$ & & & & & & & & & & \\
\hline Parveen 2018 [64] & $\mathrm{Y}$ & $\mathrm{Y}$ & $\mathrm{Y}$ & $\mathrm{Y}$ & $\mathrm{Y}$ & CT & $\mathrm{Y}$ & & & & & & & & & & \\
\hline Piil $2019[66]$ & $\mathrm{Y}$ & $\mathrm{Y}$ & $\mathrm{Y}$ & $\mathrm{Y}$ & $\mathrm{Y}$ & $\mathrm{Y}$ & $\mathrm{Y}$ & & & & & & & & & & \\
\hline Stevenson 2019 [69] & $\mathrm{Y}$ & $\mathrm{Y}$ & $\mathrm{Y}$ & $\mathrm{Y}$ & $\mathrm{Y}$ & $\mathrm{Y}$ & $\mathrm{Y}$ & & & & & & & & & & \\
\hline Tanner $2012[70]$ & $\mathrm{Y}$ & $\mathrm{Y}$ & $\mathrm{Y}$ & $\mathrm{Y}$ & $\mathrm{Y}$ & $\mathrm{Y}$ & $\mathrm{Y}$ & & & & & & & & & & \\
\hline Wright 2006 [71] & $\mathrm{Y}$ & $\mathrm{Y}$ & $\mathrm{Y}$ & $\mathrm{Y}$ & $\mathrm{Y}$ & $\mathrm{Y}$ & $\mathrm{Y}$ & & & & & & & & & & \\
\hline Wright 2006 [72] & $\mathrm{Y}$ & $\mathrm{Y}$ & $\mathrm{Y}$ & $\mathrm{Y}$ & $\mathrm{Y}$ & $\mathrm{Y}$ & $\mathrm{Y}$ & & & & & & & & & & \\
\hline \multicolumn{18}{|c|}{ Quantitative Descriptive (n=2) } \\
\hline Arain 2015 [46] & $\mathrm{Y}$ & $\mathrm{Y}$ & & & & & & $\mathrm{Y}$ & $\mathrm{Y}$ & $\mathrm{Y}$ & CT & $\mathrm{Y}$ & & & & & \\
\hline Perkins 2008 [65] & $\mathrm{Y}$ & $\mathrm{Y}$ & & & & & & $\mathrm{Y}$ & $\mathrm{Y}$ & $\mathrm{Y}$ & $\mathrm{N}$ & $\mathrm{Y}$ & & & & & \\
\hline \multicolumn{18}{|l|}{ Mixed Methods $(n=8)$} \\
\hline Bethell 2018 [48] & $\mathrm{Y}$ & $\mathrm{Y}$ & $\mathrm{Y}$ & $\mathrm{Y}$ & $\mathrm{Y}$ & CT & $\mathrm{Y}$ & $\mathrm{Y}$ & $\mathrm{Y}$ & $\mathrm{Y}$ & CT & $\mathrm{Y}$ & $\mathrm{Y}$ & $\mathrm{Y}$ & $\mathrm{Y}$ & $\mathrm{Y}$ & CT \\
\hline Bethell 2019 [49] & $\mathrm{Y}$ & $\mathrm{Y}$ & $\mathrm{Y}$ & $\mathrm{Y}$ & $\mathrm{Y}$ & $\mathrm{Y}$ & $\mathrm{Y}$ & $\mathrm{Y}$ & $\mathrm{Y}$ & $\mathrm{Y}$ & CT & $\mathrm{Y}$ & $\mathrm{Y}$ & $\mathrm{Y}$ & $\mathrm{Y}$ & $\mathrm{Y}$ & $\mathrm{Y}$ \\
\hline Chiu 2013 [7] & $\mathrm{Y}$ & $\mathrm{Y}$ & $\mathrm{Y}$ & $\mathrm{Y}$ & $\mathrm{Y}$ & $\mathrm{Y}$ & $\mathrm{Y}$ & $\mathrm{Y}$ & $\mathrm{Y}$ & $\mathrm{Y}$ & $\mathrm{Y}$ & $\mathrm{Y}$ & $\mathrm{Y}$ & $\mathrm{Y}$ & $\mathrm{Y}$ & $\mathrm{Y}$ & $\mathrm{Y}$ \\
\hline Jones $2017[58]$ & $\mathrm{Y}$ & $\mathrm{Y}$ & $\mathrm{Y}$ & $\mathrm{Y}$ & $\mathrm{Y}$ & $\mathrm{Y}$ & $\mathrm{Y}$ & $\mathrm{Y}$ & $\mathrm{Y}$ & $\mathrm{Y}$ & CT & $\mathrm{Y}$ & $\mathrm{Y}$ & $\mathrm{Y}$ & $\mathrm{Y}$ & $\mathrm{Y}$ & $\mathrm{Y}$ \\
\hline Jorgensen 2018 [60] & $\mathrm{Y}$ & $\mathrm{Y}$ & $\mathrm{Y}$ & $\mathrm{Y}$ & $\mathrm{Y}$ & $\mathrm{Y}$ & $\mathrm{Y}$ & $\mathrm{Y}$ & $\mathrm{Y}$ & $\mathrm{Y}$ & $\mathrm{Y}$ & $\mathrm{Y}$ & $\mathrm{Y}$ & $\mathrm{Y}$ & $\mathrm{Y}$ & $\mathrm{Y}$ & $\mathrm{Y}$ \\
\hline Lechelt $2018[61]$ & $\mathrm{Y}$ & $\mathrm{Y}$ & $\mathrm{Y}$ & $\mathrm{Y}$ & $\mathrm{Y}$ & $\mathrm{CT}$ & $\mathrm{Y}$ & $\mathrm{Y}$ & $\mathrm{Y}$ & $\mathrm{Y}$ & CT & $\mathrm{Y}$ & $\mathrm{Y}$ & $\mathrm{Y}$ & $\mathrm{Y}$ & $\mathrm{Y}$ & CT \\
\hline Schölvinck 2019 [67] & $\mathrm{Y}$ & $\mathrm{Y}$ & $\mathrm{Y}$ & $\mathrm{Y}$ & $\mathrm{Y}$ & $\mathrm{Y}$ & $\mathrm{Y}$ & $\mathrm{Y}$ & $\mathrm{Y}$ & $\mathrm{Y}$ & $\mathrm{N}$ & $\mathrm{Y}$ & $\mathrm{Y}$ & $\mathrm{Y}$ & $\mathrm{Y}$ & $\mathrm{Y}$ & $\mathrm{Y}$ \\
\hline Stephens $2015[68]$ & $\mathrm{Y}$ & $\mathrm{Y}$ & $\mathrm{Y}$ & $\mathrm{Y}$ & $\mathrm{Y}$ & CT & $\mathrm{Y}$ & $\mathrm{Y}$ & $\mathrm{Y}$ & $\mathrm{Y}$ & $\mathrm{Y}$ & $\mathrm{Y}$ & $\mathrm{Y}$ & $\mathrm{Y}$ & $\mathrm{Y}$ & $\mathrm{Y}$ & CT \\
\hline
\end{tabular}

wellbeing, but it should not serve to prevent initial or ongoing engagement [47]. Patients with high symptom burden and/or at end-of-life have expressed willingness and capacity for engagement in the development, conduct and dissemination of research $[47,65,66,72,75$, 76]. However, it is essential to confront researchers', clinicians and caregivers' concerns about over-burdening already frail and/or sick patients so that active and passive gatekeeping to engagement is minimized. Patients should be provided with the opportunity to accept or refuse opportunities to be engaged in research partnership in a manner that minimizes potential harm to them. The emphasis on how research partnership can and should be achieved is crucial in addressing the reservations that teams have in engaging frail and/or seriously ill patients beyond the level of consultation only.

Both patients and researchers should work to ensure clarity in patients' roles and their expected contribution throughout the study so that their input is not perceived as tokenistic $[45,46,57]$. Unintended symbolic or inauthentic gestures with frail and/or seriously ill patients assumes a greater level of magnitude, particularly when quality of life is already compromised or life-span may be limited. Providing flexibility in the timing and methods for frail and/or seriously ill patients to contribute to the research process is critical to enabling partnerships given fluctuations in health and/or cognition $[53,54,62]$. Research teams have discussed the need for 
flexibility by engaging different patients who are representative of the frail and/or seriously ill population at different points and for different tasks during the project, such as design and grant writing, tool development, peer interviews, and dissemination [7, 45, 49, 52]. Enabling partnership with frail and/or seriously ill patients requires research teams to pay extra attention to the care and comfort of their patient partners, (e.g., providing refreshments, assisting with the logistics of attending meetings, ensuring comfortable and quiet rooms, and regular touch points) $[7,45,47,53,57,62,64,70]$. The need to provide practical and emotional support has also been recognized in recent scoping reviews of patient and caregiver engagement in dementia research and palliative care research $[28,76]$.

There is ongoing deliberation about the paucity of evaluation of patient engagement in research, especially the long-term impacts related to research implementation and ongoing use of research findings [12, 22, 76, 78]. Interestingly, no reports of negative impacts on the research itself were found in the studies included in this review, which may reflect a bias in over-reporting positive impacts of patient engagement, or may suggest that evaluation efforts are more focused on short and intermediate term impacts of partnering with patients [79]. Insufficient evaluation and poor reporting of the negative impacts of patient engagement are described elsewhere in the literature and point to lack of methods and rigorous evaluation tools [22, 80]. Without validated evaluation frameworks and consistent identification of both positive and negative outcomes, there is a risk that anecdotal accounts, and perceived barriers to partnership will dominate the discourse of engagement and undermine the successes $[79,81]$.

Given the population of focus, it was surprising to have identified few negative impacts on patients. Negative outcomes were primarily defined as potential depletion of physical and emotional resources, and the likelihood of experiencing emotional distress through reliving painful illness experiences, exposure to undesirable information, or experiencing the direct suffering of others [45, 47]. It is difficult to establish whether the limited number of negative impacts identified is due to lack of evaluation or lack of reporting [12, 22, 28]. However, while a limited number of negative impacts were cited, the possible magnitude of these impacts should not be under-estimated and every effort is required by research teams to mitigate these potentially deleterious impacts. Similarly, when examining the potential impact on researchers partnering with frail and/or seriously ill patients, it is interesting to note that researchers described exposure and sensitization to the lived experience of illness and suffering, yet failed to acknowledge the concomitant emotional labor and associated burden that invariably comes with exposure to suffering [63, 82]. Issues of loss and grief are readily acknowledged for patient-partners following a decline in health or the death of others on the team [7]. However, it would appear that feelings of grief and loss, and the subsequent impact to emotional well-being, is not as readily acknowledged for researchers [82]. Failure to address these issues may leave many researchers ill-prepared to deal with emotionally demanding and difficult situations, cause unintended harm, and serve as a deterrent for both patients and researchers alike.

Evaluating the impact of partnering with frail and/or seriously ill patients is essential; limited evidence suggests that patients experienced several positive impacts, particularly when more intensive levels of engagement occurred. The potential emotional benefits described by patient partners (e.g., a renewed sense of purpose whilst coping with a disease over which they have little control, and/or the emotional support from peers on the research team) may in fact serve as a protective factor against emotional distress and vulnerability, and may also serve to quell researchers' hesitation in partnering with them $[7,45,47,51,64]$.

\section{Discontinuity of contribution}

Consistent and predictable contribution is an important consideration for teams embarking on a partnership with patients, more so for those involving frail and/or seriously ill patients on research teams. Concern for wellbeing is critical and is cited as a barrier to both initial and ongoing engagement. Discontinuity of contribution is a commonly anticipated barrier to engaging those most frail and/or ill (i.e., patients receiving palliative care, those with progressive dementia, or experiencing aggressive disease progression) [53, 70]. Patients' contribution will be lost or interrupted most often due to deterioration in their health or death, and it is incumbent on researchers to mitigate this. Paradoxically, discontinuity of contribution is rarely acknowledged when related to an improvement in condition, and yet, with advances in treatment approaches, particularly within oncology, many serious illnesses beyond the acute treatment phase are now considered chronic conditions [83]. If the purpose of including frail and/or seriously ill patients as partners in research is to provide access to the lived experience of their illness and leverage that knowledge to shape the research that is produced, the concept of discontinuity of contribution needs to be expanded to include situations when patient partners move from serious illness into remission, cure, or survivorship. The transition from serious illness to a period of more stable illness undoubtedly shifts the perspective and lived experience of patients. As such, it may be argued that over time they become less able to speak to the immediate lived experience of serious illness and more acute 
suffering. As patients are invited to participate in all stages of the research process, it is important to ensure patients within various stages of the illness trajectory are provided with equal opportunity to partner in the very research that is intended to benefit them [84].

\section{Weighing up the costs of partnership}

There are moral, ethical, and practical reasons to engage frail and/or seriously ill patients as partners in research [85]; but researchers need to consider whether the impact or benefits of their engagement is warranted by the supplementary costs they will inevitably incur [79]. Facilitators for partnering with frail and/or seriously ill patients will invariably involve additional investments of time, money, and human resources to compensate for the accompanying administrative and emotional burden that research teams undertake in the endeavor $[2,28$, 77]. Appropriate funding must be made available to teams dedicated to engaging frail and/or seriously ill patients as research partners, particularly when factoring in the need to address patients' emotional and physical needs throughout the course of engagement [7, 47]. Therefore, it is necessary to optimize efforts at patient engagement to ensure expertise of patients who truly represent illness across the trajectory, particularly with regard to frailty and/or serious illness.

\section{Strengths and limitations}

The diversity of nomenclature describing patient engagement combined with a deficiency of standardized reporting and lack of specific indexing may have resulted in some relevant studies being undetected [2, 15]. There are distinctions between what constitutes a "patient," "service user," or member of the "public," which pose additional methodological challenges for identification, recruitment and reporting [86]. Moreover, trajectories of disease progression, acute episodic exacerbation, and aggressive treatment regimens create challenges for defining frail and/or seriously ill patients [87]. To mitigate the challenges generated by issues of nomenclature and the potential fluidity of patients' condition, the search strategy was designed intentionally to be broad in order to cast a wide net for potentially relevant papers.

Further effort was taken to review the reference lists of the included studies and recently published reviews on patient engagement. To mitigate potential bias two independent reviewers were involved during study screening, data extraction, and critical appraisal. The reviewers met numerous times throughout the review process to discuss and remain consistent. All supporting files were reviewed, attention was paid to descriptors of patient condition, and associated published study protocols, where available, were traced and reviewed. Of particular relevance, one of the reviewers was a patient who was representative of being seriously ill, experiencing illness and high treatment burden at the time of the review. The second reviewer works in a direct clinical role with frail and vulnerable populations. Co-authors have clinical expertise in oncology, palliative care, frail elderly care, integrated knowledge translation, systematic review methods, and community based participatory research and were instrumental in further addressing clinical and methodological issues during the review. There were few studies reporting on the engagement of frail and/or seriously ill patients. Hence, in the spirit of transparency and inclusion, none of the lower quality studies were excluded. Interestingly, quality issues in the quantitative studies were related to the potential for non-response bias whereby those deemed too ill were not engaged as research partners.

\section{Conclusion}

Engaging frail and/or seriously ill patients as research partners has offered research teams a unique insight into understanding what it is like to live with a debilitating and fragile condition to develop research that more accurately addresses their needs. This review provides limited, but promising evidence that it is possible to successfully engage frail and/or seriously ill patients as partners in research without causing them harm. However, researchers need to ensure the purpose of engagement is well-defined, the timing and methods of inclusion are flexible, and the practical and emotional needs of patient partners are addressed. This review also highlights the need for more rigorous reporting of patient characteristics alongside the experiences, benefits, harms and impacts of their engagement in order to build best practices for engaging this vulnerable population.

\section{Supplementary information}

Supplementary information accompanies this paper at https://doi.org/10. 1186/s40900-020-00225-2.

Additional file 1: Supplementary File 1. International Association of Public Participation (IAP2) Spectrum of Public Participation.

Additional file 2: Supplementary File 2. Medline Search Terms.

Additional file 3: Supplementary File 3. PRISMA 2009 Checklist for systematic review.

\section{Abbreviations}

CINAHL: Cumulative Index to Nursing and Allied Health Literature; EMBASE: Excerpta Medica Database; IAP2: International Association of Public Participation; MEDLINE: Medical Literature Analysis and Retrieval System Online; MMAT: Mixed Methods Appraisal Tool; PCORI: Patient-Centered

Outcomes Research Institute; PICOS: Population/participants, Interventions, Comparators, Outcomes, and Study designs; PRISMA-P: Preferred Reporting Items for Systematic Reviews and Meta-Analyses Protocols; PROSPERO: Prospective Register of Systematic Reviews;

PsycINFO: Psychological Information Database 


\section{Acknowledgements}

We thank Karine Fournier, health services librarian for assistance with the development and execution of the literature search strategy. We also thank Meg Carley for assistance in manuscript preparation.

\section{Authors' contributions}

$\mathrm{CL}, \mathrm{DS}, \mathrm{IDG}$ and WG contributed to the conception of this review. All authors contributed to its design. CL led and coordinated the development and writing of the paper. IDG, DS, JL, and WG participated throughout the development and writing of the review by contributing intellectual content and feedback on drafts of the manuscript. All authors read and approved the final manuscript.

\section{Authors' information}

$\mathrm{CL}$ is a PhD Candidate in Nursing, Faculty Health Sciences at University of Ottawa. Her research interests are focused on integrated knowledge translation and how frail and/or seriously ill patients are engaged as knowledge users in research. The objectives and rationale for this review were initially conceived when she was a patient partner in a research study during a period of serious illness and acute treatment for a life-limiting disease. She was involved in all aspects of this review and has been active in dissemination of the preliminary findings.

IDG is Senior Scientist in the Clinical Epidemiology Program of the Ottawa Hospital Research Institute and Professor in the School of Epidemiology and Public Health at University of Ottawa. His extensive research focuses on knowledge translation and conducting applied research on strategies to increase implementation of research findings.

WG is Associate Professor at the University of Ottawa School of Nursing and Co-Director of the Centre for Research on Health and Nursing. Her program of research focuses on leadership and knowledge mobilization/translation to improve health care delivery and patient outcomes, and includes working with Indigenous communities in Canada.

$J$ is a Clinical Social Worker in Geriatric Psychiatry at the Royal Ottawa Mental Health Centre. Her practice is dedicated to working with the frail elderly population who have concurrent mental health issues. She is a strong advocate for inclusivity and equity of access to health and social care for vulnerable populations.

DS is Professor in the School of Nursing at the University of Ottawa and Senior Scientist at the Ottawa Hospital Research Institute, and currently holds a University Research Chair in Knowledge Translation to Patients. Her substantial research is focused on advancing the science of knowledge translation to patients and enhancing patient engagement in shared decision making.

\section{Funding}

$\mathrm{CL}$ is a recipient of a Trainee Award through the Integrated Knowledge Translation Research Network (CIHR Foundation Grant; FDN \#143237).

\section{Availability of data and materials}

Not applicable.

\section{Ethics approval and consent to participate}

Not applicable.

\section{Consent for publication \\ Not applicable.}

\section{Competing interests}

The authors declare that they have no competing interests.

\section{Author details}

'University of Ottawa, Faculty of Health Sciences, School of Nursing, Roger Guindon Hall, 451 Smyth Road, Ottawa, Ontario K1H 8M5, Canada.

2University of Ottawa, Faculty of Medicine, School of Epidemiology and Public Health, Ottawa, Ontario, Canada and Ottawa Hospital Research Institute, Clinical Epidemiology Program, 501 Smyth Road, Ottawa, Ontario K1H 8L6, Canada. ${ }^{3}$ Geriatric Psychiatry Program, Royal Ottawa Mental Health Centre, 1145 Carling Avenue, Ottawa, Ontario K1Z 7K4, Canada. ${ }^{4}$ Ottawa Hospital Research Institute, Clinical Epidemiology Program, 501 Smyth Road, Ottawa, Ontario K1H 8L6, Canada.
Received: 30 April 2020 Accepted: 27 July 2020

Published online: 11 September 2020

\section{References}

1. Barber R, Boote JD, Parry GD, Cooper CL, Yeeles P, Cook S. Can the impact of public involvement on research be evaluated? A mixed methods study. Health Expect. 2012:15:229-41.

2. Domecq JP, Prutsky G, Elraiyah T, Wang Z, Nabhan M, Shippee N, et al. Patient engagement in research: a systematic review. BMC Health Serv Res. 2014;14:89.

3. Bowen SJ, Graham ID. From knowledge translation to engaged scholarship: promoting research relevance and utilization. Arch Phys Med Rehabil. 2013;94:S3-8.

4. de Wit M, Elberse JE, Broerse JEW, Abma TA. Do not forget the professional - the value of the FIRST model for guiding the structural involvement of patients in rheumatology research. Health Expect. 2015;18:489-503.

5. Sibbald SL, Tetroe J, Graham ID. Research funder required research partnerships: a qualitative inquiry. Implement Sci. 2014;9:176.

6. Ross LF, Loup A, Nelson RM, Botkin JR, Kost R, Smith GR, et al. Human subjects protections in community-engaged research: a research ethics framework. J Empir Res Hum Res Ethics. 2010:5:5-17.

7. Chiu CG, Mitchell TL, Fitch Ml. From patient to participant: enhancing the validity and ethics of cancer research through participatory research. J Cancer Educ. 2013;28:237-46.

8. Robillard JM, Feng TL. When patient engagement and research ethics collide: lessons from a dementia forum. J Alzheimers Dis. 2017;59:1-10.

9. Howe A, Mathie E, Munday D, Cowe M, Goodman C, Keenan J, et al. Learning to work together - lessons from a reflective analysis of a research project on public involvement. Res Involv Engagem. 2017;3:1.

10. OSSU. Ontario SPOR SUPPORT Unit. (2020). https://ossu.ca/about-us/. Accessed 23 Apr 2020

11. Canadian Institutes Health Research. Guide to knowledge translation planning at CIHR: Integrated and end of grant approaches. (2012). http://www.cihr-irsc. gc.ca/e/documents/kt_Im_ktplan-en.pdf. Accessed 23 Apr 2020.

12. Manafo $E$, Petermann L, Mason-Lai P, Vandall-Walker V. Patient engagement in Canada: a scoping review of the 'how' and 'what' of patient engagement in health research. Health Res Policy Syst. 2018;16(1):5-11.

13. Greenhalgh T, Hinton L, Finlay T, Macfarlane A, Fahy N, Clyde B, et al. Frameworks for supporting patient and public involvement in research: systematic review and co-design pilot. Health Expect. 2019;22:785-801.

14. Jull JE, Davidson L, Dungan R, Nguyen T, Woodward KP, Graham ID. A review and synthesis of frameworks for engagement in health research to identify concepts of knowledge user engagement. BMC Med Res Methodol. 2019;19(1):211-13

15. Shippee ND, Garces J, Domecq JP, Lopez GJ, Wang Z, Elraiyah TA, et al. Patient and service user engagement in research: systematic review and synthesized framework. Health Expect. 2015;18:1151-66.

16. Canadian Institutes of Health Research. Strategy for Patient-Oriented Research - Patient Engagement Framework. (2014). http://www.cihr-irsc.gc ca/e/48413.html. Accessed 8 Feb 2019.

17. Hewlett $S$, de Wit M, Richards $P$, Quest E, Hughes R, Heiberg $T$, et al. Patients and professionals as research partners: challenges, practicalities, and benefits. Arthritis Care Res. 2006;55:676-80.

18. Armstrong MJ, Mullins CD, Gronseth GS, Gagliardi AR. Impact of patient involvement on clinical practice guideline development: a parallel group study. Implement Sci. 2018;13:55

19. Hyde C, Dunn KM, Higginbottom A, Chew-Graham CA. Process and impact of patient involvement in a systematic review of shared decision making in primary care consultations. Health Expect. 2017;20:298-308.

20. Armstrong N, Herbert G, Aveling EL, Dixon-Woods M, Martin G. Optimizing patient involvement in quality improvement. Health Expect. 2013;16:e36-47.

21. Caron-Flinterman JF, Broerse JEW, Bunders JFG. Patient partnership in decisionmaking on biomedical research. Sci Technol Human Values. 2007;32:339-68.

22. Brett J, Staniszewska S, Mockford C, Herron-Marx S, Hughes J, Tysall C, et al. A systematic review of the impact of patient and public involvement on service users, researchers and communities. Patient. 2014;7:387-95.

23. Maccarthy J, Guerin S, Wilson AG, Dorris ER. Facilitating public and patient involvement in basic and preclinical health research. PLoS One. 2019;14: e0216600.

24. Collins K, Boote J, Ardron D, Gath J, Green T, Ahmedzai SH. Making patient and public involvement in cancer and palliative research a reality: academic support is vital for success. BMJ Support Palliat Care. 2015;5:203-6. 
25. Ocloo J, Matthews R. From tokenism to empowerment: progressing patient and public involvement in healthcare improvement. BMJ Qual Saf. 2016;25: 626-32.

26. Clarke $\mathrm{CL}$, Wilkinson $\mathrm{H}$, Watson J, Wilcockson J, Kinnaird L, Williamson T. A seat around the table: participatory data analysis with people living with dementia. Qual Health Res. 2018;28:1421-33.

27. Swarbrick CM, Doors O, Educate K, Davis J, Keady J. Visioning change: coproducing a model of involvement and engagement in research (innovative practice). Dementia. 2016. https://doi.org/10.1177/ 1471301216674559.

28. Bethell J, Commisso E, Rostad HM, Puts M, Babineau J, Grinbergs-Saull A, et al. Patient engagement in research related to dementia: a scoping review. Dementia. 2018:17:944-75.

29. Puts MTE, Sattar S, Ghodraty-Jabloo V, Hsu T, Fitch M, Szumacher E, et al Patient engagement in research with older adults with cancer. J Geriatr Oncol. 2017:8:391-6

30. Zaslavsky O, Cochrane BB, Thompson HJ, Woods NF, Herting JR, LaCroix A. Frailty. Biol Res Nurs. 2013;15:422-32.

31. Somes J. What is frailty? J Emerg Nurs. 2017;43:272-4

32. Sampson EL. Frailty and dementia: common but complex comorbidities. Aging Ment Health. 2012;16:269-72.

33. Kelley AS, Covinsky KE, Gorges RJ, McKendrick K, Bollens-Lund E, Morrison RS, et al. Identifying older adults with serious illness: a critical step toward improving the value of health care. Health Serv Res. 2017;52:113-31.

34. Moher D, Shamseer $L$, Clarke M, Ghersi D, Liberati A, Petticrew M, et al. Preferred reporting items for systematic review and meta-analysis protocols (PRISMA-P) 2015 statement. BMJ. 2015;349:7647.

35. International Association of Public Participation (IAP2) Public Participation Spectrum. www.iap2canada.ca/Resources/Documents/0702-FoundationsSpectrum-MW-rev2 (1).pdf Accessed 22 Feb 2019.

36. Crockett LK, Shimmin C, Wittmeier KDM, Sibley KM. Engaging patients and the public in Health Research: experiences, perceptions and training needs among Manitoba health researchers. Res Involv Engagem. 2019;5:28.

37. Covidence systematic review software, Veritas Health Innovation, Melbourne, Australia. [Internet]. Veritas Health Innovation. 2019. Available from: www.covidence.org. Accessed April 2019.

38. Houghton C, Murphy K, Meehan B, Thomas J, Brooker D, Casey D. From screening to synthesis: using nvivo to enhance transparency in qualitative evidence synthesis. J Clin Nurs. 2017;26:873-81.

39. Hong QN, Pluye P, Fàbregues S, Bartlett G, Boardman F, Cargo M, Dagenais P, Gagnon M-P, Griffiths F, Nicolau B, O'Cathain A, Rousseau M-C, Vedel I. Mixed Methods Appraisal Tool (MMAT), version 2018. Registration of Copyright (\#1148552), Canadian Intellectual Property Office, Industry Canada.

40. Pluye P, Hong QN. Combining the power of stories and the power of numbers: mixed methods research and mixed studies reviews. Annu Rev Public Health. 2014:35:29-45.

41. Souto RQ, Khanassov V, Hong QN, Bush PL, Vedel I, Pluye P. Systematic mixed studies reviews: updating results on the reliability and efficiency of the mixed methods appraisal tool. Int J Nurs Stud. 2015;52:500-1.

42. Pace R, Pluye P, Bartlett G, Macaulay AC, Salsberg J, Jagosh J, et al. Testing the reliability and efficiency of the pilot Mixed Methods Appraisal Tool (MMAT) for systematic mixed studies review. Int J Nurs Stud. 2012;49:47-53.

43. Hong QN, Gonzalez-Reyes A, Pluye P. Improving the usefulness of a tool for appraising the quality of qualitative, quantitative and mixed methods studies, the Mixed Methods Appraisal Tool (MMAT). J Eval Clin Pract. 2019; 24:459-67.

44. Moher D, Liberati A, Tetzlaff J, Altman DG, The PRISMA Group. Preferred reporting items for systematic reviews and meta-analyses: the PRISMA statement. PLoS Med. 2009;6(7):e1000097.

45. Absolom K, Holch P, Woroncow B, Wright E, Velikova G. Beyond lip service and box ticking: how effective patient engagement is integral to the development and delivery of patient-reported outcomes. Qual Life Res. 2015;24:1077-85.

46. Arain M, Pyne S, Thornton N, Palmer S, Sharma RA. Consumer involvement in cancer research: example from a Cancer network. Health Expect. 2015;18:1530-42.

47. Bates MJ, Ardrey J, Mphwatiwa T, Squire SB, Niessen LW. Enhanced patient research participation: a Photovoice study in Blantyre Malawi. BMJ Support Palliat Care. 2018;8:171-4.

48. Bethell J, Pringle D, Chambers LW, Cohen C, Commisso E, Cowan K, et al. Patient and public involvement in identifying dementia research priorities. J Am Geriatr Soc. 2018;66:1608-12.
49. Bethell J, Puts MTE, Sattar S, Andrew MK, Choate AS, Clarke B, et al. The Canadian frailty priority setting partnership: research priorities for older adults living with frailty. Can Geriatr J. 2019;22:23-33.

50. Burns $\sqcup$, Abbetti B, Arnold SD, Bender J, Doughtie S, El-Jawahiri A, et al. Engaging patients in setting a patient-centered outcomes research agenda in hematopoietic cell transplantation. Biol Blood Marrow Transplant. 2018;24:1111-8.

51. Caldon LJM, Marshall-Cork H, Speed G, Reed MWR, Collins KA. Consumers as researchers - innovative experiences in UK National Health Service Research. Int J Consum Stud. 2010;34:547-50.

52. Corner J, Wright D, Hopkinson J, Gunaratnam Y, McDonald JW, Foster C. The research priorities of patients attending UK cancer treatment centres: findings from a modified nominal group study. Br J Cancer. 2007;96:875-81.

53. Cotterell P, Harlow G, Morris C, Beresford P, Hanley B, Sargeant A, et al. Service user involvement in cancer care: the impact on service users. Health Expect. 2011;14:159-69.

54. Davis SF, Silvester A, Barnett D, Farndon L, Ismail M. Hearing the voices of older adult patients: processes and findings to inform health services research. Res Involv Engagem. 2019;5:11.

55. Froggatt K, Preston $\mathrm{N}$, Turner $\mathrm{M}$, Kerr $\mathrm{C}$. Patient and public involvement in research and the Cancer experiences collaborative: benefits and challenges. BMJ Support Palliat Care. 2015:5:518-21.

56. Heaven A, Brown L, Foster M, Clegg A. Keeping it credible in cohort multiple randomised controlled trials: the community ageing research $75+$ (CARE 75+) study model of patient and public involvement and engagement. Res Involv Engagem. 2016;2:30.

57. Iwata AJ, Olden HA, Kippen KE, Swegal WC, Johnson CC, Chang SS. Flexible model for patient engagement: achieving quality outcomes and building a research agenda for head and neck cancer. Head Neck. 2019;41:1087-93.

58. Jones J, Bhatt J, Avery J, Laupacis A, Cowan K, Basappa N, et al. The kidney cancer research priority-setting partnership: identifying the top 10 research priorities as defined by patients, caregivers, and expert clinicians. Can Urol Assoc J. 2017:11:379-87.

59. Jorgensen CR, Eskildsen NB, Johnsen AT. User involvement in a Danish project on the empowerment of cancer patients - experiences and early recommendations for further practice. Res Involv Engagem. 2018;4:26.

60. Jorgensen CR, Eskildsen NB, Thomsen TG, Nielsen ID, Johnsen AT. The impact of using peer interviewers in a study of patient empowerment amongst people in cancer follow-up. Health Expect. 2018;21:620-7.

61. Lechelt LA, Rieger JM, Cowan K, Debenham BJ, Krewski B, Nayar S, et al. Top 10 research priorities in head and neck cancer: results of an Alberta priority setting partnership of patients, caregivers, family members, and clinicians. Head Neck. 2018;40:544-54.

62. Litherland R, Burton J, Cheeseman M, Campbell D, Hawkins M, Hawkins T, et al. Reflections on PPI from the 'Action on living well: asking you' advisory network of people with dementia and carers as part of the IDEAL study. Dementia. 2018;17:1035-44.

63. Littlechild R, Tanner D, Hall K. Co-research with older people: perspectives on impact. Qual Soc Work. 2015;14:18-35.

64. Parveen S, Barker S, Kaur R, Kerry F, Mitchell W, Happs A, et al. Involving minority ethnic communities and diverse experts by experience in dementia research: the caregiving HOPE study. Dementia. 2018;17:990-1000.

65. Perkins P, Booth S, Vowler SL, Barclay S. What are patients' priorities for palliative care research? A questionnaire study. Palliat Med. 2008:22:7-12.

66. Piil K, Jarden M, Pii KH. Research agenda for life-threatening cancer. Eur J Cancer Care (Engl). 2019;28:e12935.

67. Schölvinck AFM, de Graaff BMB, van den Beld MJ, Broerse JEW. Research in haematological cancers: what do patients in the Netherlands prioritise? Eur J Cancer Care (Engl). 2019;28(2):e12989.

68. Stephens RJ, Whiting C, Cowan K. Research priorities in mesothelioma: a James Lind Alliance priority setting partnership. Lung Cancer. 2015;89(2): 175-180.

69. Stevenson M, Taylor BJ. Involving individuals with dementia as coresearchers in analysis of findings from a qualitative study. Dementia. 2019; 18:701-12.

70. Tanner D. Co-research with older people with dementia: experience and reflections. J Ment Health. 2012;21:296-306.

71. Wright D, Corner J, Hopkinson J, Foster C. Listening to the views of people affected by cancer about cancer research: an example of participatory research in setting the cancer research agenda. Health Expect. 2006;9:3-12.

72. Wright D, Hopkinson J, Corner J, Foster C. How to involve cancer patients at the end of life as co-researchers. Palliat Med. 2006;20:821-7. 
73. Piil K, Jarden M. Patient involvement in research priorities (PIRE): a study protocol. BMJ Open. 2016;6:e010615.

74. Perkins $\mathrm{P}$, Barclay $\mathrm{S}, \mathrm{Booth} \mathrm{S}$. What are patients' priorities for palliative care research? Focus group study. Palliat Med. 2007;21:219-25.

75. Pii KH, Schou LH, Piil K, Jarden M. Current trends in patient and public involvement in cancer research: a systematic review. Health Expect. 2019;22:3-20.

76. Chambers E, Gardiner C, Thompson J, Seymour J. Patient and carer involvement in palliative care research: an integrative qualitative evidence synthesis review. Palliat Med. 2019;33:969-84.

77. Holroyd-Leduc J, Resin J, Ashley L, Barwich D, Elliott J, Huras P, et al. Giving voice to older adults living with frailty and their family caregivers: engagement of older adults living with frailty in research, health care decision making, and in health policy. Res Involv Engagem. 2016;2:23.

78. Gagliardi AR, Kothari A, Graham ID. Research agenda for integrated knowledge translation (IKT) in healthcare: what we know and do not yet know. J Epidemiol Community Health. 2017;71:105-6.

79. Oliver K, Kothari A, Mays N. The dark side of coproduction: do the costs outweigh the benefits for health research? Health Res Policy Syst. 2019;17:33.

80. Boivin A, L'Esperance A, Gauvin FP, Dumez V, Macaulay AC, Lehoux P, et al. Patient and public engagement in research and health system decision making: a systematic review of evaluation tools. Health Expect. 2018;21: 1075-84.

81. Manafo E, Petermann L, Vandall-Walker V, Mason-Lai P. Patient and public engagement in priority setting: a systematic rapid review of the literature. PLoS One. 2018;13:e0193579-e.

82. Boylan A, Locock L, Thomson R, Staniszewska S. "About sixty per cent I want to do it": health researchers' attitudes to, and experiences of, patient and public involvement (PPI)—a qualitative interview study. Health Expect. 2019; 22:721-30.

83. Phillips JL, Currow DC. Cancer as a chronic disease. Collegian. 2010;17:47-50.

84. Ciccarella A, Staley AC, Franco AT. Transforming research: engaging patient advocates at all stages of cancer research. Ann Transl Med. 2018;6:167.

85. Ives J, Damery S, Redwod S. PPI, paradoxes and Plato: Who's sailing the ship? J Med Ethics. 2013;39:181-5.

86. Forbat L, Hubbard G, Kearney N. Patient and public involvement: models and muddles. J Clin Nurs. 2009;18:2547-54.

87. Camp P, Reid W, Yamabayashi C, Brooks D, Goodridge D, Chung F, et al. Safe and effective prescription of exercise in acute exacerbations of chronic obstructive pulmonary disease: rationale and methods for an integrated knowledge translation study. Can Respir J. 2013;20:281-4.

\section{Publisher's Note}

Springer Nature remains neutral with regard to jurisdictional claims in published maps and institutional affiliations.

Ready to submit your research? Choose BMC and benefit from:

- fast, convenient online submission

- thorough peer review by experienced researchers in your field

- rapid publication on acceptance

- support for research data, including large and complex data types

- gold Open Access which fosters wider collaboration and increased citations

- maximum visibility for your research: over $100 \mathrm{M}$ website views per year

At $\mathrm{BMC}$, research is always in progress.

Learn more biomedcentral.com/submissions 